\title{
Limitations and Promise of Retinal Tissue From Human Pluripotent Stem Cells for Developing Therapies of Blindness
}

\author{
Ratnesh K. Singh* and Igor O. Nasonkin* \\ Lineage Cell Therapeutics, Alameda, CA, United States
}

The self-formation of retinal tissue from pluripotent stem cells generated a tremendous promise for developing new therapies of retinal degenerative diseases, which previously seemed unattainable. Together with use of induced pluripotent stem cells or/and CRISPR-based recombineering the retinal organoid technology provided an avenue for developing models of human retinal degenerative diseases "in a dish" for studying the pathology, delineating the mechanisms and also establishing a platform for large-

OPEN ACCESS

Edited by:

Carla Mellough

Lions Eye Institute, Australia

Reviewed by:

Bela Volgyi,

University of Pécs, Hungary

Elisabetta Catalani,

University of Tuscia, Italy

${ }^{*}$ Correspondence:

Ratnesh K. Singh

ratnein@gmail.com

Igor O. Nasonkin

igor.nasonkin@outlook.com

Specialty section:

This article was submitted to

Cellular Neuropathology,

a section of the journal

Frontiers in Cellular Neuroscience

Received: 26 February 2020

Accepted: 25 May 2020

Published: 10 September 2020

Citation:

Singh RK and Nasonkin 10 (2020)

Limitations and Promise of Retinal

Tissue From Human Pluripotent Stem

Cells for Developing Therapies

of Blindness.

Front. Cell. Neurosci. 14:179.

doi: 10.3389/fncel.2020.00179 scale drug screening. At the same time, retinal organoids, highly resembling developing human fetal retinal tissue, are viewed as source of multipotential retinal progenitors, young photoreceptors and just the whole retinal tissue, which may be transplanted into the subretinal space with a goal of replacing patient's degenerated retina with a new retinal "patch." Both approaches (transplantation and modeling/drug screening) were projected when Yoshiki Sasai demonstrated the feasibility of deriving mammalian retinal tissue from pluripotent stem cells, and generated a lot of excitement. With further work and testing of both approaches in vitro and in vivo, a major implicit limitation has become apparent pretty quickly: the absence of the uniform layer of Retinal Pigment Epithelium (RPE) cells, which is normally present in mammalian retina, surrounds photoreceptor layer and develops and matures first. The RPE layer polarize into apical and basal sides during development and establish microvilli on the apical side, interacting with photoreceptors, nurturing photoreceptor outer segments and participating in the visual cycle by recycling 11-trans retinal (bleached pigment) back to 11-cis retinal. Retinal organoids, however, either do not have RPE layer or carry patches of RPE mostly on one side, thus directly exposing most photoreceptors in the developing organoids to neural medium. Recreation of the critical retinal niche between the apical RPE and photoreceptors, where many retinal disease mechanisms originate, is so far unattainable, imposes clear limitations on both modeling/drug screening and transplantation approaches and is a focus of investigation in many labs. Here we dissect different retinal degenerative diseases and analyze how and where retinal organoid technology can contribute the most to developing therapies even with a current limitation and absence of long and functional outer segments, supported by RPE.

Keywords: retinal organoids, disease modeling, pluripotent stem cells, retinal degeneration, photoreceptors, assembloids, drug screening, retinal pigment epithelium 


\section{INTRODUCTION}

Retina is a great model for developmental neuroscience and a very attractive therapeutic target for biotech companies working in the field of regenerative medicine. There are only several types of retinal neurons (rod and cone photoreceptors, amacrine, horizontal, rod \& cone bipolar and retinal ganglion cells), one type of glial cells (Muller glia) and a pigmented layer of supportive cells (Retinal pigment epithelium), which form the retina and help to carry out visual function (Wallace, 2011). On the contrary, the cortical organization in the brain is much more complex and has six layers of cortical neurons, each carrying different cell types with different function (Molyneaux et al., 2007; Lodato and Arlotta, 2015). This relative simplicity creates a promise for ease of recapitulation of this process in a dish (compared to brain), as well as (expected) relative ease of cell replacement therapies (again, compared to the brain). This, in turn, is very attractive to regenerative medicine and biotechnology, which aim to convert the already "understood" and "worked out" knowledge and concepts into robust technologies and therapies to transition science from the bench to patients. Age related macular degeneration (AMD), glaucoma and retinitis pigmentosa (RP) are the major retinal degenerative diseases affecting people worldwide. Understanding the causes and mechanisms of these diseases (outlined below) is a key for developing organoidbased in vitro models of these diseases for drug screening and disease modeling.

According to eye health data and statistics, summarized on NEI's web site ${ }^{1}$ and in a recent study published by Varma et al. (2016), the number of people with most common eye diseases is going to double by 2050. AMD is a leading cause of vision loss in United States and mainly affects the central vision. According to statistics presented by Brightfocus foundation ${ }^{2}$ about 11 million of Americans have visual problem associated with AMD symptoms, and this number is projected only to increase and reach 22 million by 2050. The total number of people with macular degeneration worldwide is projected to be 196 million by now (2020) and 288 million by year 2040 . About $30 \%$ of people age 75 and above have vision problems associated with AMD symptoms. Macular degeneration triggers loss of central vision and death of photoreceptors in the macula (maculae) (Molday, 1998; Molday and Moritz, 2015). The dry form of AMD accounts for 85 to 90 percent of all AMD cases (Klein et al., 1992; Bird et al., 1995; Vingerling et al., 1995). In dry AMD disruption and death of RPE causes accrual of yellow deposit (drusen) in the macula that contributes to accumulation of complement component and acute phase proteins leading to proinflammatory macrophage response (Ding et al., 2009) and eventually photoreceptor cell death. Geographic atrophy (GA) is devastating complication of dry AMD and is considered the late stage of this disease affecting more than 5 million people worldwide including nearly 1 million in the United States 4 (Bird et al., 1995; Wong et al., 2014) (Friedman et al., 2004;

\footnotetext{
${ }^{1}$ https://www.nei.nih.gov/learn-about- eye-health/resources-for-healtheducators/eye-health-data-and-statistics

${ }^{2}$ https://www.brightfocus.org/macular/article/age-related-macular-facts-figures
}

Rudnicka et al., 2015.Geographic atrophy is a frequent cause of legal blindness ( $42 \%$ of patients with GA) (Klein et al., 1995) and severe ( $\geq 6$ lines) vision loss (Sunness et al., 1999). Transplantation of human pluripotent stem cell (hPSC) derivedRPE into the subretinal space is one experimental therapy (in clinical trials now), which may address this condition (Schwartz et al., 2012, 2015, 2016; McGill et al., 2017; Cuzzani, 2018) and is aimed to support photoreceptors and prevent their cell death. In wet (also neovascular or exudative) $A M D$ the abnormal growth of blood vessels (also known as choroidal neovascularization, $\mathrm{CNV}$ ) beneath the macula causes separation between photoreceptors and RPE (Yeo et al., 2019). This is the only blinding disease, which has a robust treatment via suppressing neovasculogenesis with anti-Vascular Endothelial Growth Factor (VEGF) therapies (Meadows and Hurwitz, 2012) such as antibodies (or antibody fragments) to (bevacizumab, ranibizumab) (Rosenfeld et al., 2006; Raftery et al., 2007), VEGF-A soluble decoy (aflibercept) (Sarwar et al., 2016) or/and small molecules suppressing the tyrosine kinases induced by VEGF binding (lapatinib, sunitinib, pazopanib and a few other compounds). Glaucoma is another leading cause of irreversible vision loss. From 2011 to 2050, the number of people in the U.S. with glaucoma is expected to increase from 2.71 million in year 2011 to 3.72 million in year 2020 to 7.32 million by year 2050 (Vajaranant et al., 2012). Glaucoma affects retinal ganglion cells, carrying the visual signals from retina to brain, It is caused (mostly) by elevated intraocular pressure followed by loss of retinal ganglion cells and their axons (Weinreb et al., 2014) and impacts long-distance connectivity between the retina and the visual centers in the brain (discussed earlier). In retinitis pigmentosa, or rod-cone dystrophy (a group of inherited, mostly recessive diseases characterized by the onset of night blindness and gradual loss of peripheral vision, prevalence $\sim 1: 3500$ to $1: 4,000$ ) loss of rod photoreceptor cells triggers the late stage degeneration of cone photoreceptors even though specific mutation affects only rods but no cones (Kaplan et al., 2017). Once the photoreceptors die it causes remodeling of inner retinal neurons and followed by cell death of inner retinal cells (Singh et al., 2014). In addition, cone-rod dystrophies (inherited retinal dystrophies/maculopathies, prevalence 1:40,000) (Hamel, 2007) and Leber Congenital Amaurosis (very early-onset child blindness, usually autosomal-recessive, prevalence 1-2:100,000, source $^{3,4}$ ) add to the number of devastating blinding diseases affecting people and causing loss of life quality and partial loss of independence.

At present, there is no effective treatment available for most of these retinal disorders (except for wet AMD) despite most of the studies done on animal (mostly rodent) models to find new therapeutic options for retinal diseases. Rodent models can mimic only certain aspect of human retinal pathophysiology. They fail to reproduce the etiologic complexity of human RD diseases, including and especially some critically important characteristics of the primate retina like macula (Zeiss, 2010) [rodents don't have macula (Volland et al., 2015a); cats and

\footnotetext{
${ }^{3}$ https://rarediseases.org/rare-diseases/leber-congenital-amaurosis/

${ }^{4}$ https://ghr.nlm.nih.gov/condition/leber-congenital-amaurosis
} 
dogs have area centralis (Petersen-Jones, 1998; Mowat et al., 2008)] or trichromacy important for visual acuity in patients (Kostic and Arsenijevic, 2016), and do not always mimic the retinal disease phenotype (Slijkerman et al., 2015). Nevertheless, the neuroanatomical structure and connectivity of young retinal organoids growing in a dish is very similar to the developing human fetal retina, which is being explored as new way to study early stages of human retinal development (Meyer et al., 2009). However, all studies, where retinal organoids were cultured for prolonged period of time ( 6 months or longer), note the gradual changes in retinal organoids (specifically, gradual loss of RGCs and thinning of INL) (Wahlin et al., 2017; DiStefano et al., 2018; Brooks et al., 2019; Capowski et al., 2019; Nasonkin et al., 2019), thus substantially reducing the ability to model diseases and derive therapeutically meaningful results from drug screening efforts. Human retinal tissue in a dish has a real potential to be a great tool for drug screening, as well as disease modeling and source of transplantable $3 \mathrm{D}$ retina for RP and AMD after these critical shortcomings of retinal organoid technology are addressed. Scientific retinal community is keenly aware of the immense potential of human retinal organoid technology and the urgency of addressing these critical deficiencies in organoid technologies, preventing us to use it to the fullest extent for basic and translational research and regenerative medicine treatments. However, even now some remarkable success has been achieved with modeling treatments of some types of blindness (e.g., some ciliopathies) in retinal organoids, highlighting precise disease mechanisms and new potential therapies, which could be challenging to decipher and discover in cultured cells and time-consuming in animals (Schwarz et al., 2017).

In this review, we discuss the biology of retinal organoids and similarities with human retinal development, translational applications of retinal organoids in disease modeling (based on today's technology state), cell or tissue replacement and discuss current major limitations of retinal organoid technology and how to overcome it. We provide a brief summary for each blinding disease (RP, AMD, glaucoma) to be aware of the current limitations as well as opportunities of retinal organoids as a tool for designing such models in a dish. We also use this summary throughout the text to discuss the key basic and translational research directions needed now to improve the retinal organoid models and technologies to enable faithful recapitulation of retinal biology, homeostasis and diseases in a dish for developing new drugs, delineating disease mechanisms and designing 3-Dimensional transplantable retina for replacement therapies.

We pay special attention to highlighting similarities and differences between human retinal organoids and human fetal and mature retinal tissue, and the impact of these similarities and differences on our ability to interrogate disease mechanisms, screen for drugs and use organoids for cell and tissue replacement therapies. Last, we present our opinion on how the technology will be developing in the next 3-7 years to focus on addressing the current limitations and urgent needs of biotech sector for developing therapies (drugs, biologics) using retinal organoids as a tool.

\section{RETINAL ORGANOIDS FOR BASIC BIOLOGY AND TRANSLATIONAL STUDIES}

\section{Modeling Early Retinal Development Early Cell Fate Decisions and Studying the Role of Morphogens}

Ongoing retinogenesis in $3 \mathrm{D}$ retinal tissue derived from hPSCs (ES and iPS) recapitulate early stages of human retinal development (Meyer et al., 2009; Volkner et al., 2016) (Figure 1). A number of very informative and well-designed retinal cell fate studies in young organoids were done by Gamm lab, which uncovered the instructive signaling of WNT and FGFs and decisions between NR and RPE fate (Capowski et al., 2016; Gamm et al., 2019). Developing retinal organoids (even without RPE) seem to be a good model for dissecting such major cell fate decisions, cell cycle, number of progenitors of each cell type and their initial organization in developing mammalian retina. Nevertheless, one should be mindful of some differences such as lack of RPE and lens and changes in the extrinsic factors and morphogen gradients caused by these differences (Dakubo et al., 2008; Smith et al., 2018). Though these signaling cues have some major consequences for translational research (e.g., $\mathrm{BMP} / \mathrm{TGFb}$ signaling from ocular surface ectoderm through Smad4, also modulated HH signaling (Li et al., 2016), these are very early developmental processes (NR vs RPE), typically related to microphthalmia (Bharti et al., 2006; Manuel et al., 2008; Bharti et al., 2012) and marginally related to RD diseases.

\section{Retinal Ganglion Cell Development}

Retinal ganglion cell development takes place early in retinogenesis (Marquardt and Gruss, 2002), and young retinal organoids ( $\sim 6-15$ weeks) derived by various methods carry RGCs (Singh et al., 2015), which are typically detected with antibodies to BRN3A, BRN3B, ISL-1, sometimes SNCG, HuC/D, neuronal-specific class III $ß$-Tubulin (TUJ-1 antibody) and/or Thy-1 (Barnstable and Drager, 1984; Huang et al., 2006). A number of labs pursuing RGC development successfully study RGC development, early stages of axonogenesis and axon guidance in retinal organoids (Fligor et al., 2018). In the absence of their natural target (visual centers in the brain (Cruz-Martin et al., 2014; Dhande and Huberman, 2014; Ray and Kay, 2015) RGC axons may even traverse through the retinal tissue (Singh et al., 2015) but eventually degenerate, together with RGC cell bodies (Wahlin et al., 2017; Capowski et al., 2019; Nasonkin et al., 2019). This is because RGCs need connectivity with the brain to receive flow of neurotrophins; RGC axotomy models and cases of anencephalic brain (both severing this vital to RGC connection) indicate rapid degeneration of RGCs in human fetal retina (Mo et al., 2002; Nakazawa et al., 2002; van Adel et al., 2005; Hendrickson et al., 2006). With the conceptualization and development of assembloid technologies co-culturing of retinal and brain organoids became feasible (Gopalakrishnan, 2019; Pacitti et al., 2019). This extends the developmental window for RGC studies in retinal organoid model which can now include studies interrogating mechanisms guiding RGC projections to 


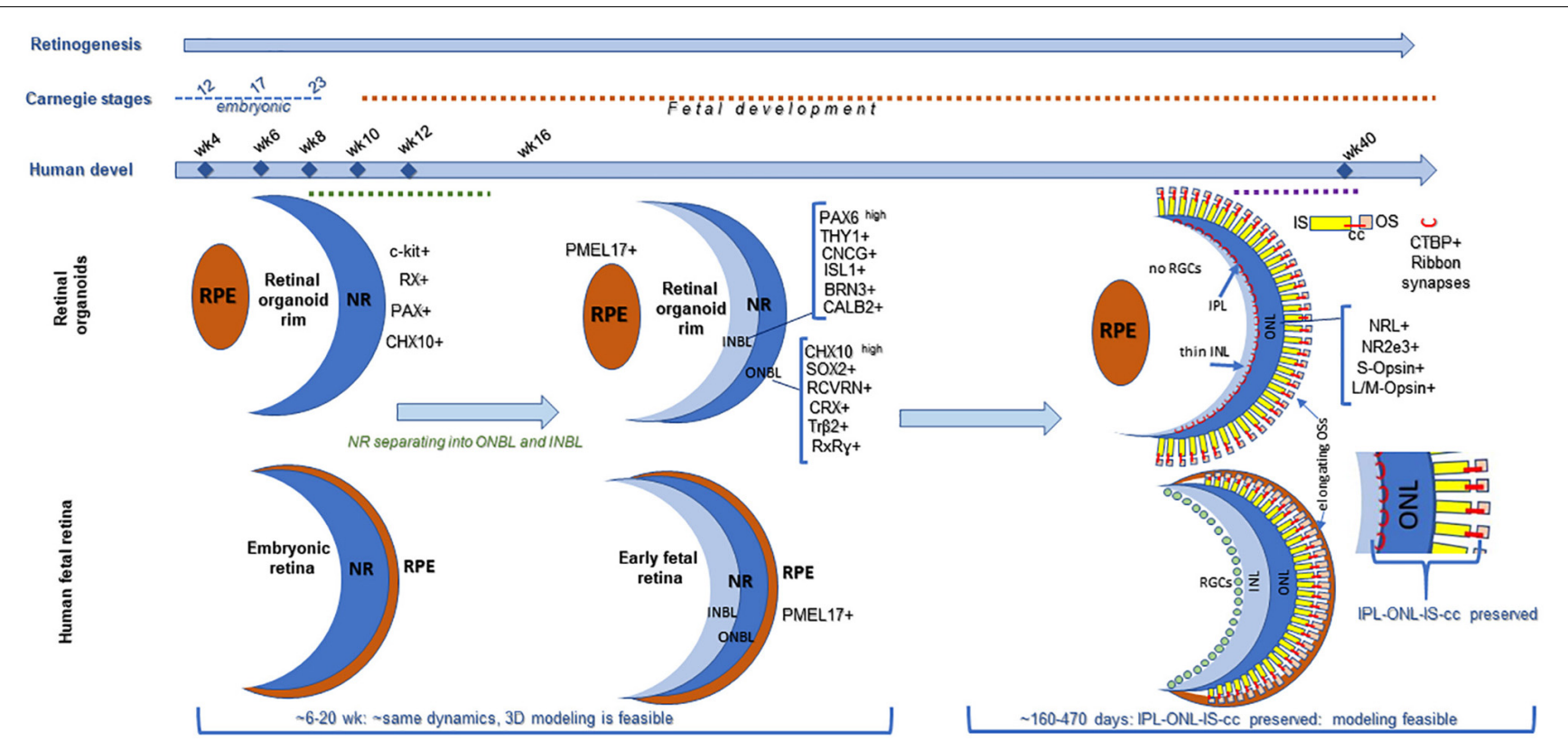

FIGURE 1 | Comparing retinogenesis between human pluripotent stem cell derived retinal organoid growing in a dish and in human fetal retina. Both retinal organoids and fetal retina develop neural retina (NR), but only fetal retina (not organoids) develop continuous layer of RPE surrounding NR (Stage1). Both fetal retina and retinal organoids undergo lamination (Stage 2), and develop outer and inner neuroblast layers (ONBL, where progenitors, including photoreceptor progenitor and young photoreceptors localize, and INBL, where RGCs and $2^{\text {nd }}$ order neurons migrate). However, as tissue maturation proceeds in retinal organoids, the RGCs gradually die (no connectivity) and then a layer of $2^{\text {nd }}$ order neurons becomes progressively thinner. And, while cilia and inner segments in photoreceptors develop, outer segments never elongate full-length, compared to that in mature mammalian retina (Stage 3$)$. In fetal retina ( $2^{\text {nd }}->3^{\text {rd }}$ trimester) photoreceptor layer undergoes maturation, cilia and inner segments are formed and elongation of outer segments takes place (which continues after birth). Organoids at stage3 preserve the features of immature human retina (IPL-ONL-IS-cc region, shown). This diagram is designed based on the following data: https://embryology.med.unsw.edu.au/ embryology/index.php/Vision_-_Retina_Development, https://embryology.med.unsw.edu.au/embryology/index.php/Carnegie_Stage_Comparison, https:// embryology.med.unsw.edu.au/embryology/index.php/Carnegie_stage_table (O'Brien et al., 2004; Hendrickson et al., 2008; Jukic et al., 2013; Hendrickson, 2016; Hoshino et al., 2017).

brain (Kurimoto et al., 2010; de Lima et al., 2012; Erskine and Herrera, 2014; Crair and Mason, 2016; Benowitz et al., 2017; Laha et al., 2017).

\section{INL \& Outer Plexiform Synaptic Layer}

Several long-term in vitro and in vivo studies investigated connectivity of second order neurons (rod bipolar neurons, typically stained with anti-PKC $\alpha$ antibody) and photoreceptors in human and mouse retinal organoids (Wahlin et al., 2017; Capowski et al., 2019) and in vivo, between graft or host-specific bipolar neurons and graft-specific photoreceptors (Assawachananont et al., 2014; Gonzalez-Cordero et al., 2017; $\mathrm{Tu}$ et al., 2018). The formation of CTBP2[+] horseshoelike ribbon synapses (Singh et al., 2014; Singh et al., 2017) was documented by both IHC and electron microscopy in organoids cultured for 5-6 months or longer by several teams. In the in vivo studies, where the INL-specific organoid cells (including the bipolar neurons) continue to be lost, graft-specific photoreceptors were found in contact with (in some cases) graftspecific and (in some other cases) host-specific bipolar neurons (Assawachananont et al., 2014; Shirai et al., 2016; Tu et al., 2018). Collectively, these studies demonstrate that connectivity at the OPL level in organoids and in grafts is feasible, which lays foundation for tissue replacement work using hESC-3D retinal tissue from organoids as source of transplantable tissue. In anticipation of improved 3D human retinal models with functional RPE-photoreceptor niche and photoreceptor-second order neuron connectivity, it becomes important to focus on defining cone bipolar-photoreceptor connectivity and cone bipolar cell markers. The classical cone bipolar marker Recoverin (RCVRN) (Milam et al., 1993; Euler and Wassle, 1995) is also strongly expressed in CRX $[+]$ photoreceptor progenitors (Singh et al., 2015) and $\alpha$-RCVRN staining is the method of choice for defining photoreceptor layer in retinal organoids. Because of the major emphasis of translational retinal work on AMD (in addition to glaucoma) for building models of human macula and designing transplantable retina for patients with advanced AMD, delineating new reliable markers of cone bipolar cells for demonstrating cone bipolar-cone photoreceptor connectivity in organoids and in subretinal grafts may be critical for moving such modeling and transplantation work forward. Some excellent new markers were recently described (Shekhar et al., 2016).

\section{Photoreceptors (Rod and Cone)}

Photoreceptors (rod and cone) in retinal organoids are the key cell types in retinal organoids, which seem to remain organized in a uniform layer in long-term organoid cultures (Wahlin et al., 2017; Capowski et al., 2019; Nasonkin et al., 
2019), and (in addition to RGCs) represent the primary drugscreening target for Big Pharma companies. Pioneering work has been done in human fetal retina by researchers like Drs. Anita Hendrickson, Tom Reh, Anand Swaroop and others to elucidated human retinal development with emphasis on photoreceptors (Abramov et al., 1982; O’Brien et al., 2004; Hendrickson et al., 2008; Hendrickson, 2016; Chao et al., 2017). A layer of photoreceptors with NRL[+] rods (Swaroop et al., 1992), OPN1SW[+] (S-cones) and TRß2[+] (Ng et al., 2001) M-cones robustly forms in organoids derived by multiple techniques, which highlights retinal organoids as a good model of human photoreceptor genesis and maturation in a $3 \mathrm{D}$ tissue in a dish. This enables to dissect the important of multiple small molecules, morphogens and canonical signaling pathways such as basic fibroblast growth factor (bFGF), docosahexaenoic acid, bone morphogenic protein (BMP), taurine, Retinoic Acid (RA), WNT (Wingless) (Murali et al., 2005; Pandit et al., 2015; Zhong et al., 2014; Capowski et al., 2016, 2019; Brooks et al., 2019; Gamm et al., 2019) important for photoreceptor development. Methods outlining mostly cone photoreceptor development from CRX $[+]$ photoreceptor progenitors will be instrumental for modeling human macula in a dish as well as for designing transplantable $3 \mathrm{D}$ retinal grafts for treating patients with advanced AMD (Zhou et al., 2015).

\section{SIGNALING PATHWAYS INVOLVED IN HUMAN RETINAL DEVELOPMENT, DERIVATION OF RETINAL ORGANOIDS AND POSTMITOTIC MAINTENANCE OF BOTH TISSUES}

Human retinal organoids recapitulate stages of human embryonic and early fetal retinal development (Meyer et al., 2009; Volkner et al., 2016; Gonzalez-Cordero et al., 2017) (Figure 1) and use the same pathways, active in developing human embryonic and early fetal retina for retinogenesis (Hoshino et al., 2017). The embryonic patterning and cell fate decisions in embryogenesis in general are regulated by very conserved developmental cues throughout the animal phyla (Perrimon et al., 2012). Human retinal development is not an exception and is shaped by the same cues and pathways (Heavner and Pevny, 2012). Some of these pathways also participate in maintaining retinal homeostasis. The importance of the complex interplay of these pathways in formation and further maturation of 3D human retinal tissue in a dish (organoids) only recently became a subject of thorough investigation (Hoshino et al., 2017). Understanding of this complexity will help with developing better retinal tissue-in-a-dish models with all retinal layers and functional RPE/photoreceptor niche for biopharmaceutical companies for drug screening (; Aasen and Vergara, 2020), and better retinal transplants for curing advanced retinal degenerative diseases (Assawachananont et al., 2014; Mandai et al., 2017a; McLelland et al., 2018; Shirai et al., 2016; Singh et al., 2019). Retina develops from the anterior portion of the neural tube through evagination of the optic vesicles from diencephalon, followed by invagination of those vesicles to form the optic cups carrying RPE and neural retina (NR) layers (consisting of the multipotential retinal progenitors) (collectively, "retina") (Adler and Canto-Soler, 2007; Bharti et al., 2006; Fuhrmann et al., 2014). Invagination of each optic cup also leads to the formation of the optic stalk (the precursor of the optic nerve), which then becomes the optic nerve after the invagination of the stalk and closure of the choroid fissure (Remington, 2012; Forrester et al., 2016). MITF[+] RPE layer and CHX10 (same as VSX2[+]) NR layer carrying multipotential retinal progenitorsgive rise to the retinaand are collectively called "retina" (though some call NR "retina", in contrast to $\mathrm{RPE}$ ). Following their formation, RPE consistently remains as a single, layer, accumulates pigmentation and undergoes gradual maturation (Bharti et al., 2006, 2012), while NR undergoes a fascinating process of retinogenesis, where multipotential retinal progenitors sequentially acquire cell fate and form different types of retinal neurons and Muller glia (Livesey and Cepko, 2001; Marquardt and Gruss, 2002; Cayouette et al., 2006; Matsushima et al., 2011; Bassett and Wallace, 2012). Rod and cone photoreceptor cell fate acquisition and development is part of this retinogenesis process, and leads to the formation of the therapeutically valuable light-sensing outer nuclear layer (ONL) consisting of rods and cones (Swaroop et al., 2010; $\mathrm{Ng}$ et al., 2011). The default pathway in rod versus cone photoreceptor cell fate acquisition is cone PRs (specifically short-wave cones, S-cones) (Swaroop et al., 2010; Hunt and Peichl, 2014; Zhou et al., 2015). This pathway is promoted by blocking Bone Morphogenic Protein signaling (BMP), also WNT and TGFß signaling in culture (Zhou et al., 2015), and mutations of $N R L$ or NR2E3 genes in vivo (enhanced S-cone syndrome) (Mears et al., 2001; Sharon et al., 2003; Cheng et al., 2006; Littink et al., 2018). The expression of transcription factor Neural Leucine Zipper $(N R L)$ at about week 10.5 of human fetal development defines rod photoreceptor cell fate (Swaroop et al., 1992; Mears et al., 2001; Hendrickson et al., 2008) and NR2E3 (activated by $N R L$, at about week 11.7 in human fetal retinal development) (O’Brien et al., 2004; Cheng et al., 2006) further strengthens rod PR identity. Both of these transcription factors are expressed prominently in rod PRs in retinal organoids. Waves of signaling mediated by WNT, FGF, Hedgehog, BMP/TGFb NOTCH, Retinoic acid (RA) and IGF-1 pathways through retina shape retinal development from earlier stages toward the completion of retinogenesis (Yaron et al., 2006; Liu et al., 2006; Das et al., 2008; Fuhrmann, 2008; Fuhrmann, 2010; Fujimura, 2016; Mills and Goldman, 2017). Signaling via diffusible ligands is also present in postmitotic retina (Chen et al., 2015). These principles of development neurobiology combined with pluripotent stem cell technology are used for derivation of retinal organoids (good summary was provided in Dr. Sally Temple's review Zhao et al., 2017). While some of these morphogen gradients seem to be present in retinal organoids (e.g., WNT pathway, judged by the presence of LGR5 and SFRP1 on the apical and basal side (Figures 2, 3) some other key gradients may be completely or partially absent due to lack of choroid, retinal vasculature and a continuous layer of RPE around the organoids. Exploring these signaling pathways in retinal organoids and comparing them to 


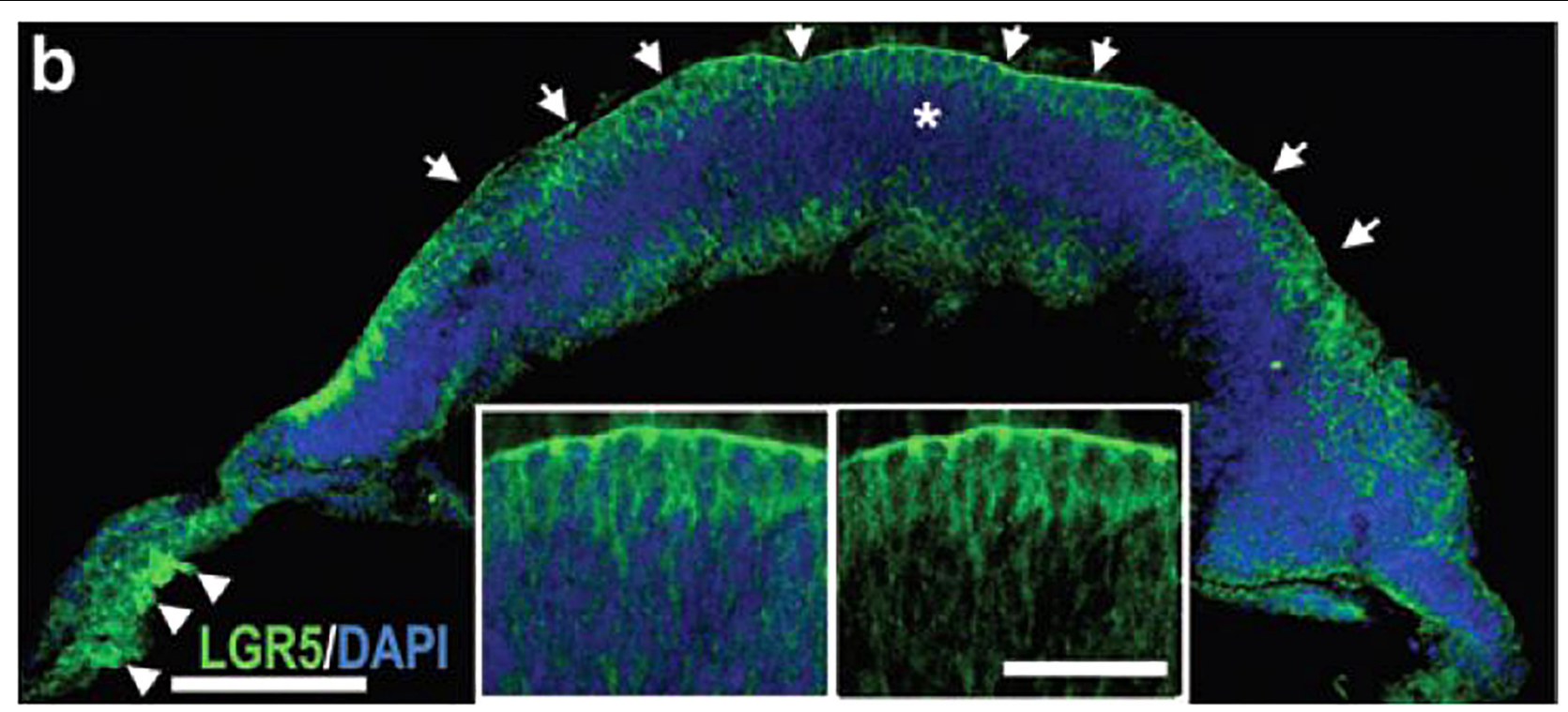

FIGURE 2 | Presence of LGR5 in retinal organoids. Immunostaining of human pluripotent stem cell derived retinal organoid with anti-LGR5 antibody.

signaling in developing and postmitotic mammalian retina will improve the development of better $3 \mathrm{D}$ in vitro models of human retina, which may be particularly critical for drug development.

\section{WNT in Retina and Organoids}

WNT is one of the most studied pathways in developing mammalian retina (Liu et al., 2006; Fuhrmann, 2008; Liu et al., 2010; Fujimura, 2016). Leucine rich repeat containing G proteincoupled receptor 5 (LGR5), a member of the G protein-coupled, 7-transmembrane receptor (GPCR) superfamily, is a receptor for R-spondins, and potentiates the canonical WNT signaling (de Lau et al., 2014). LGR5 is highly expressed in developing retinal organoids (300 fold) (Singh et al., 2015) and also present in developing human fetal retina (Chen et al., 2015). Formation of retinal organoids can be promoted by modulation of WNT pathway (Takata et al., 2017; Luo et al., 2018). WNT signaling remains important in postmitotic retina (Yao et al., 2016). WNT and Notch pathways acting together are known to regulate stem cell niches (birth, renewal and maintenance of multipotential stem cells, in short, stemness (Androutsellis-Theotokis et al., 2006; Clevers et al., 2014; Kessler et al., 2015) in tissues, including in the organoids (Kessler et al., 2015). Modulating these pathways in retinal organoids may be an interesting approach to study retinal regeneration and stemness (Jiang et al., 2020) to replenish cells lost in ageing, trauma or due to degenerative conditions.

\section{Sonic Hedgehog (SHH)}

Sonic Hedgehog (SHH) and members of the Hedgehog (HH) family (Indian- and Desert Hedgehog, IHH and $\mathrm{DHH}$ ) are well studied in developing vertebrate retina (Levine et al., 1997; Neumann and Nuesslein-Volhard, 2000; Nguyen and Arnheiter, 2000; Vogel-Hopker et al., 2000; Zhang and Yang, 2001a,b; Wang et al., 2002; Dakubo et al., 2003, 2008; Spence et al., 2004; Locker et al., 2006; Yu et al., 2006), including mammalian retina, more relevant to the biology of human retinal organoids, and provide very important paracrine signaling cues. There seem to be two major sources of $\mathrm{HH}$ signaling, one coming from RGCs (Wang et al., 2002), and another from choroid/RPE (from endothelial cells Dakubo et al., 2008, also from RPE Nakayama et al., 1998; Perron et al., 2003) impacting RPE (Zhang and Yang, 2001b; Burnett et al., 2017; May-Simera et al., 2018) and likely photoreceptors (Levine et al., 1997). $\mathrm{HH}$ signaling impacts retinal progenitor proliferation and cell fate determination (Wang et al., 2002; Sakagami et al., 2009). Cilia is needed for SHH signaling and is very important part of both types of cells forming the subretinal niche (photoreceptors Gilliam et al., 2012; Rachel et al., 2012a,b; Yildiz and Khanna, 2012; Wheway et al., 2014 and RPE May-Simera et al., 2018). Problems with cilia development, structure and functions result in ciliopathies, and many of them involve RD conditions because of importance of primary cilia for visual transduction, RPE-photoreceptor connectivity and outer segment function (Chen H.Y. et al., 2019). RPE cilia length had a noticeable change in Dnmt1 conditional mutants with short outer segment, hypoplastic apical RPE and retinal degeneration (Nasonkin et al., 2013). Pharmacological drugs were found, which promote apical RPE maturation in hiPSC-RPE and promote cilia formation. In relation to $\mathrm{SHH}$, the integrity and shape of cilia impact $\mathrm{SHH}$ signaling efficacy, dependent on cholesterol (derived from OS membranes) (Myers et al., 2013; Bangs and Anderson, 2017; Garcia et al., 2018; Kinnebrew et al., 2019; Kong et al., 2019). Cilia is present in maturing hPSC-retinal organoids $\sim 5-6$ month and older (demonstrated by our lab (Nasonkin et al., 2019) and others (Wahlin et al., 2017; Hallam et al., 2018; Capowski et al., 2019). With cholesterol provided via FBS (Yang et al., 2014) (critically needed for further growth of organoids) (Zhong et al., 2014) and photoreceptor cilia present in organoids $\sim 5-6$ month old and older, SHH signaling is probably reconstituted in tissue culture. 


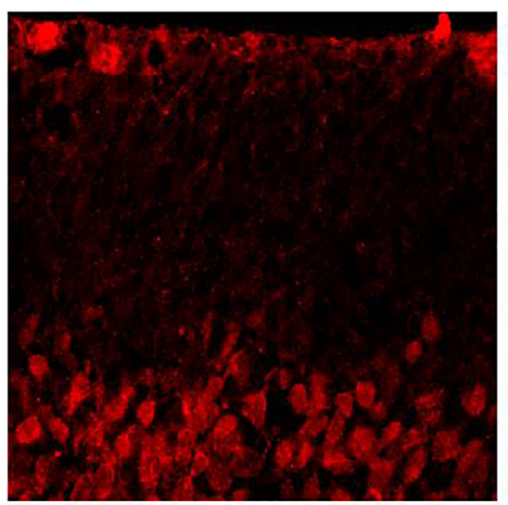

SFRP1

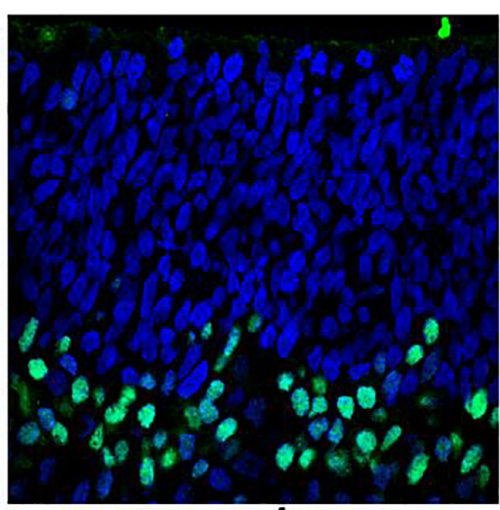

BRN3B/DAPI

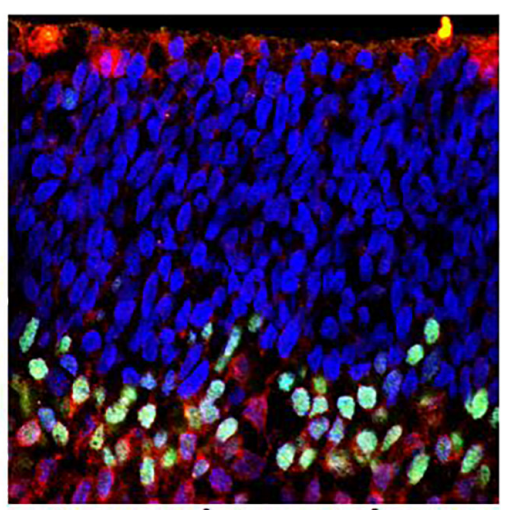

SFRP1/BRN3B/DAPI

FIGURE 3 | Localization of SFRP1 in human fetal retina. Immunostaining of human fetal retina (wk10) with anti-SFRP1 and anti-BRN3B antibody shows SFRP1 presence in the apical side of ONBL and distal side of INBL. Anti BRN3B colocalized with SFRP1 in the INBL.

However, once the co-culture system between photoreceptor sheet in retinal organoids and the RPE (or RPE/choroid) sheet is created, this signaling will become closer to the one present in mammalian subretinal niche.

\section{FGF1 and 9}

FGF1 and 9 are important for neural retina formation (less for cell fate specification Cai et al., 2010 except for RGCs Chen et al., 2013) and then for photoreceptor survival and maintenance (Fontaine et al., 1998; Qin et al., 2011; Hochmann et al., 2012), and were used to enhance NR cell fate in mouse models and in vitro in hPSC- > retinal differentiation systems (2D and 3D) at the expense of RPE (Pittack et al., 1997; Zhao et al., 2001; Horsford et al., 2005; Cai et al., 2010; Hambright et al., 2012; Gamm et al., 2019). Separately, some lower (reduced) level of basic fibroblast growth factor (bFGF) signaling (Moore et al., 2004) but not the complete abrogation of FGF signaling (Meyer et al., 2009) is needed for initial eye field specification. FGF morphogens are potentially a great tool to enrich for neural retina cell fate in organoids and 2D monolayer cultures. However, in view of the importance for developing better in vitro retinal models with RPE and NR growing together for studying and treating $\mathrm{RD}$ diseases, it seems that keeping the developmentally relevant balance of these factors, rather than completely abrogating RPE cell fate in developing retinal organoids, may be the right approach for developing better $3 \mathrm{D}$ retinal models. Nevertheless, investigating neuroprotective abilities of FGFs for promoting photoreceptor survival (Fontaine et al., 1998; Qin et al., 2011; Hochmann et al., 2012) seems a doable and therapeutically relevant approach in 6-12 - month old organoids, where the predominant surviving cell type is rod and cone photoreceptors.

\section{BMP and TGF $\beta$ Signaling}

Contribution of BMP signaling is important in retinal development for determination of NR identity (Murali et al., 2005; Pandit et al., 2015) and originates from developing lens (Pandit et al., 2015), ocular surface ectoderm (Li et al.,
2016) as well as retinal neurons (Close et al., 2005), RPE and vasculature (summarized in $\mathrm{Ma}$ et al., 2019). Activin A signaling through SMAD2/3 was found to increase number of photoreceptor precursors during retinal differentiation in $2 \mathrm{D}$ adherent monolayer (Lu et al., 2017). BMP/TGFb (and SHH) pathways modulation were used for derivation of organoids from human embryonic stem cells (hESCs) (Hallam et al., 2018; Kuwahara et al., 2019). Constitutive TGF $\beta$ signaling is needed in postmitotic retina (Ma et al., 2019). TGF $\beta$ (b1, b2, b3) are expressed by multiple developing and postmitotic retinal cell types including neurons, vasculature, RPE and microglia (Lutty et al., 1991; Lutty et al., 1993; Siegert et al., 2012; Close et al., 2005; Ma et al., 2019). Excessive TGF $\beta$ signaling causes epithelial to mesenchymal transition (EMT) in RPE and proliferative vitreoretinopathy (PVR) and fibrosis, while Cre-mediated deletion of $T G F \beta$ in the whole eye and in vascular endothelium (but not RPE) caused choroidal neovascularization (CNV) (Schlecht et al., 2017). Both EMT- > PVR and CNV cause secondary changes in retina causing photoreceptor degeneration. These signaling are very relevant and important for developing vision restoration therapies (Kobayashi et al., 2019). However, in the absence of vasculature and subretinal niche in organoids we are so far limited in the ability to study them in the $3 \mathrm{D}$ retinal organoid model. A major source of BMPs and TGFs in retinal organoid culture is clearly delivered exogenously, with addition of $5-10 \%$ fetal bovine serum (FBS), and adding FBS is critical for maturation and growth (but not formation) of retinal organoids (Zhong et al., 2014). Modulating BMP-4 level in developing retinal organoids may help generate NR with RPE at the margin (ciliary margin-like zone, CMZ) (Kuwahara et al., 2015), which is a step in the right direction toward generating physiologically and therapeutically relevant 3D NR-RPE models (the subretinal niche).

NOTCH pathway is frequently mentioned when discussing retinal progenitor cell (RPC) proliferation/maintenance and specification, asymmetric cell division via Numb (where one RPC daughter acquires cell fate while another proceeds with symmetric cell division) (Shen et al., 2002; Ha et al., 2017) 
as well as regenerative cues in retina supporting retinal tissue regeneration (Mills and Goldman, 2017). Notch signaling in retina (which involves 4 receptors) works via paracrine ligands (Ha et al., 2017), with downstream signaling cascade involving RBP-J transcription factor (Riesenberg et al., 2009; Zheng et al., 2009) and Hes1/Hes5 (Yaron et al., 2006). Inactivation of RBP$\mathrm{J}$ and modulation of Notch pathway with inhibitors (DAPT being the most well-known $\gamma$-secretase/Notch pathway inhibitor) impacts the formation of NR, retinal lamination and may impact PR yield (Tomita et al., 1996; Yaron et al., 2006; Zheng et al., 2009), as well as determination of other cell types (Furukawa et al., 2000) depending on timing of Notch pathway inactivation during retinogenesis. Retinal cell types are born sequentially during retinogenesis (Livesey and Cepko, 2001; Marquardt and Gruss, 2002). Notch pathway promotes cell cycle progression in multipotential retinal progenitors (Yaron et al., 2006), while Notch suppression causes premature exit from a cell cycle, causing premature birth of later-developing cell types (Tomita et al., 1996). Therefore, it is clear that when Notch pathway is blocked earlier in retinal development (when e.g., cone PRs are developing), such modulation may increase cone PR yield (Yaron et al., 2006). This knowledge has been used productively for modulating the number of different cell types in human and mouse retinal organoids (Volkner et al., 2016). Because of the involvement of Notch1 in regeneration and major differences in species in the ability to regenerate retinal tissue we focused this paragraph mostly on reports outlining the role of Notch pathway in mammalian retina. Critically to retinal organoids (which usually do not have a sheet of RPE cells around PRs (Zhong et al., 2014). Notch signaling is active in RPE as well (providing signaling cues to nearby RPCs (Ha et al., 2017; Liu et al., 2013). Ablation of RPE in mouse development severely impacts retinal layer organization (lamination) (Raymond and Jackson, 1995). Likewise, lamination defects occur in two RBPJ -knockout mouse models (Riesenberg et al., 2009; Zheng et al., 2009) (summarized in Zheng et al., 2010), potentially pointing to the need of active Notch signaling (via RPE or diffusible Notch ligands) for organoid growth and contributing to retinal lamination in organoids. It is likely that serum provides some level of Notch ligands as it is needed for organoid growth (Zhong et al., 2014) and RPE-free lamination in retinal organoids has been reported (Capowski et al., 2019).

\section{Insulin-Like Growth Factor 1 (IGF-1)}

Insulin-like growth factor 1 (IGF-1)is one of the pathways, which was instrumental for derivation of retinal progenitors from hESCs in 2D adherent monolayers (Lamba et al., 2006; Lamba et al., 2010; Hambright et al., 2012) and 3D retinal organoids (Mellough et al., 2015; Singh et al., 2015). IGF-1 is a very important extrinsic factor (morphogen) in developing retina and was shown to promote proliferation multipotential retinal progenitors (RPCs) via PI3K/Akt and MAPK/Erk pathways (Wang et al., 2018) and rod photoreceptor precursors in the fish (teleost) retina (Mack and Fernald, 1993). IGF-1 signaling in general regulates tissue growth and development in embryogenesis by supporting cell survival and cell cycle progression (Schlueter et al., 2007). The transition of rod photoreceptor precursors to mature post-mitotic rod photoreceptors is also promoted by IGF-1 (Yi et al., 2005; Pinzon-Guzman et al., 2011) and is regulated (at least partially) by phosphatidylinositide concentration and 3-phosphoinositidedependent protein kinase-1 (PDPK-1) (Xing et al., 2018). IGF1 receptor immunoreactivity is present in the ONBL (where photoreceptor progenitors reside in developing retina and retinal organoids) and in ONL of postmitotic mammalian retina (Greenlee et al., 2006). Another report mapped IGF-1 receptor (IGF-1R) as well as insulin receptor, IR, predominantly to photoreceptors and blood vessels, with very low level in other retinal cell types (Lofqvist et al., 2009). IGF-1 is also a component of FBS (Singh and Armstrong, 1997), and, given the importance of IGF-1 for photoreceptor maintenance [above and (Arroba et al., 2009)] as well as RPE maintenance (Zheng et al., 2018) and the need of growing organoids for serum (Zhong et al., 2014), IGF-1 will likely be included in serum-free ("defined media") culturing methods of long-term organoid/RPE culture in the next few years. In addition, data from Igf- $1^{-/-}$mutant mice (a model of human neurosensory syndromic deafness/blindness) indicated the gradual loss of ERGs, retinal morphology and significant loss of connectivity between photoreceptors and their synaptic partners (loss of bassoon and synaptophysin) while only small changes in the INL (Rodriguez-de la Rosa et al., 2012), highlighting the importance of IHG-1 pathway for photoreceptors and the need for IGF-1 in long-term photoreceptor-RPE cultures.

\section{Retinoic Acid (RA)}

Retinoic Acid (RA) is one of the best studied signaling pathways, active and important in many tissues during embryonic patterning and organogenesis (Rhinn and Dolle, 2012). Retinoic acid signaling is important at several stages of mammalian eye development, including promoting retinogenesis (Osakada et al., 2008, 2009; Cvekl and Wang, 2009; Lamba et al., 2010). Vitamin $\mathrm{A}$ and RA are indispensable for eye development and participate in several stages of eye and retina development (Matt et al., 2005; Cvekl and Wang, 2009). Early in development, Raldh2 expression in the optic vesicle enables generation of RA signal needed for invagination of retina to form an optic cup (Mic et al., 2004). Retinoic Acid, a biologically active Vitamin A (retinol) derivative, serves as a ligand for nuclear receptors regulating gene expression (Duester, 2000; Duester, 2009) and regulates the expression of the key rod photoreceptor cell fate gene NRL (Khanna et al., 2006). However, the continuing presence of RA negatively impacts photoreceptor maturation (Nakano et al., 2012). Exposure to exogenous RA increased the number of rod and green cone photoreceptors and decreased the number of blue and UV cone opsin cells in zebrafish (Prabhudesai et al., 2005), suggesting RA as an instrumental factor in retinal organoid culture contributing to rod-cone photoreceptor development. The enzyme involved in RA synthesis (RALDH2) has been localized to RPE. Mimicking RA signaling in young retinal organoids for promoting photoreceptor development is now part of many protocols and can be done with addition of RA to differentiation medium (Zhong et al., 2014; Wahlin et al., 2017; Capowski et al., 2019). Retinol/RA was localized to photoreceptor 
outer segments in long-term retinal organoid cultures (Capowski et al., 2019) and light-responsive (mature) retinal organoids have been generated (Hallam et al., 2018). However, restoring the chemistry of the retinoid (visual) cycle (Kiser et al., 2014) and recycling of all-trans-retinol back to 11-cis retinal by RPE (canonical pathway for chromophore recycling) (Saari, 2000; Wang et al., 2009) for natural reintroduction into photoreceptor outer segments seems unattainable until the establishment of long-term co-culture between sheets of photoreceptors in retinal organoids and RPE and rebuilding of functional photoreceptorRPE subretinal niche.

\section{Pigment Epithelium Derived Factor (PEDF, or SERPINF1)}

Pigment epithelium derived factor (PEDF, or SERPINF1) signaling is an important paracrine and autocrine pathway in retina (Tombran-Tink et al., 1991; Malchiodi-Albedi et al., 1998; Tombran-Tink and Barnstable, 2003) for maintaining PR-RPE niche (Volpert et al., 2009; Akiyama et al., 2012), photoreceptor maturation (Jablonski et al., 2000; Akhtar et al., 2019) and survival (Comitato et al., 2018; Chen Y. et al., 2019). PEDF expression is a hallmark of RPE maturation and polarization (Strunnikova et al., 2010; Maruotti et al., 2015; McGill et al., 2017). High level of PEDF expression is produced by RPE differentiated from human pluripotent stem cells (Kanemura et al., 2013; Maruotti et al., 2015; Geng et al., 2017; McGill et al., 2017).

Pigment epithelium derived factor has a pleiotropic impact on many pathways, is considered a neuroprotective factor in retina and among other functions, may potentially have immunomodulatory function (Dawson et al., 1999; Gregerson et al., 2006; Ho et al., 2011; Chuderland et al., 2013; Nelius et al., 2013; Idelson et al., 2018). In view of increasing interest in co-culturing systems between photoreceptor sheets in retinal organoids and RPE sheets for recreating the subretinal niche, better $3 \mathrm{D}$ in vitro long-term retinal disease modeling as well as designing transplantable retinal patches, PEDF may become one of the important factors for establishing such cultures and maintaining homeostasis in vitro between the photoreceptors and RPE.

\section{D RETINAL TISSUE MODELS FOR ELUCIDATING DISEASE MECHANISMS \& DRUG DISCOVERY}

Though developmental biology questions were driving the discovery of retinal organoids, most work quickly shifted toward translational applications because of the unique ability to use organoids as a tool to design human retinal diseases in a dish (Figure 4). 3D-retinal organoids grown in a dish are developmentally, anatomically and physiologically similar to retinal tissue in vivo. Such ability has huge implication in disease modeling with organoids (Lancaster and Huch, 2019) although further improvements, particularly in formation of RPE and photoreceptor interaction and scalability, are definitely needed
(Jin et al., 2011). Generation of human induced pluripotent stem cells (hiPSCs) from patients with retinal disease and further differentiating them to retinal organoid provide deep insight in understanding retinal diseases.

A number of studies have recently used retinal organoid for understanding retinal diseases (Jin et al., 2011), caused by photoreceptor degeneration (RP, AMD). Because most RP diseases are single-gene autosomal recessive, many RPs represent a very attractive target for organoid technologies for modeling and drug development.

Screening for small molecules ameliorating $\mathrm{RD}$ critically depends on the quality of model (retina-in a dish). For example, most RD diseases originate in the RPE-PR niche (either in PRs or/and RPE) and not having RPE-PR interaction in human retina-in-a-dish significantly impacts our ability to model these diseases (and screening for drugs preventing these RDs). Likewise, screening for drugs to ameliorate glaucoma (number one blinding disease) is so far challenging because RGCs degenerate in maturing retinal organoids (by $\sim 6$ month in culture) (Capowski et al., 2019) due to the absence of the projection targets for RGCs (superior colliculus, lateral geniculate nucleus). However, a number of diseases focused on diseases originating at the level of photoreceptors can be studied and modeled. As one example, retinitis pigmentosa-39 (RP39) is caused by homozygous or compound mutations in USH2A gene, which encodes protein Usherin, required for photoreceptor (also hair cells in the cochlea) maintenance because of its role in cilia formation and function (Liu et al., 2007). In a study by Guo et al. the team reprogrammed cells from RP39 patient carrying (c.8559-2A > G/c.9127_9129delTCC) to iPSCs, generated mature retinal organoids from iPSC line with USH2A mutation and found significant defects in photoreceptor morphology with defective retinal progenitor cell development and retinal layer formation compared to control (Guo et al., 2019). Transcription profiling done on mutant retinal organoid revealed increase in apoptotic genes and abnormal gene expression compared to control. In another study iPSCs lines generated from three RPGR mutant patients [RP3 (Rozet et al., 2002), also RP15, cone-rod degeneration, X-linked (Mears et al., 2000)] were used for differentiation to retinal organoids (Deng et al., 2018). The team observed defects in photoreceptor morphology and localization, changes in transcriptional profiling and electrophysiological activity, in line with knowledge about the disease mechanisms. Interestingly, shortened cilium was found in patient iPSCs and RPE and photoreceptors in retinal organoids, derived from those iPSCs. Similarly, Megaw et al. (2017) showed that iPSCs-derived photoreceptors from RPGR mutation patients exhibited increased actin polymerization compared to the control, which was due to a disruption of cell signaling pathways regulating actin turnover via disruption of RPGR-Gelsolin interaction, which impacts Gelsolin activation (Megaw et al., 2017). Therefore, this study uncovered a disease mechanisms (loss of RPGR-mediated Gelsolin activation) using patient's iPSC- derived retinal organoids as a tool, cheaper and faster than an animal model, and therefore identified a druggable pathway, amenable for regulation with small molecules. 


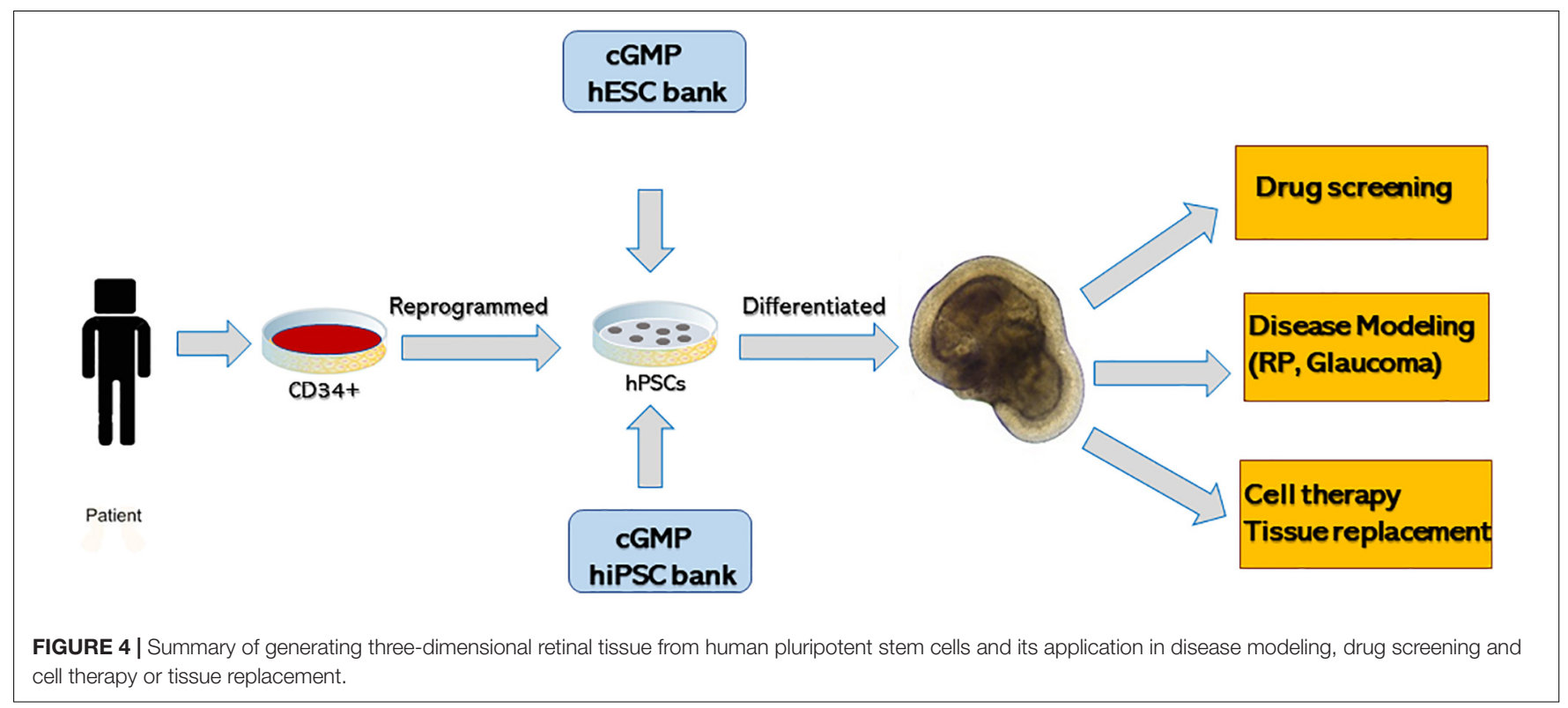

Study by Schwarz et al. (2017) identified interacting partners (Kif7 and Kif17) of the RP2 protein [GTP-ase activating protein (Veltel et al., 2008)] and observed reduced kinesin Kif7 (a conserved regulator of $\mathrm{HH}$ signaling) and Kif17 staining at photoreceptor cilia tips in iPSC-derived 3D optic cups from a patient with the X-linked $R P 2$ nonsense mutation c.519C > T (p. R120X) compared to control mutation-free organoids (Schwarz et al., 2017). The team was able to correct the PR2 defect by using translational read-through drugs, collectively elucidating the disease mechanism/etiology and highlighting the potential therapeutic approach to treat the disease. Kif7 (together with another ciliary protein Kif17) is reported to play a role in stabilizing cilia tips yet prior to this study multiple other studies done in various models including zebrafish, $C$. elegans and mice failed to elucidate the precise mechanism of this blinding ciliopathy disorder [reviewed in Schwarz et al. (2017)]. Interestingly, the study from another group done in mice indicated that loss of RP2 protein is associated with cone but not rod photoreceptor defects and leads to abnormal extension of cone outer segments (Li et al., 2015).

In yet another study focused on iPSCs disease modeling of RP Masayo Takahashi's team derived iPSCs from a patient with a RHO mutation, derived retinal organoids and demonstrated that photoreceptors in organoids recapitulate the disease phenotype and display signs of endoplasmic reticulum stress (Jin et al., 2012), typical feature in RHO models of RD (Kroeger et al., 2014).

\section{What RD Diseases Caused by PR Degeneration Can and Cannot $\mathrm{Be}$ Modeled so Far}

From these examples it is evident that modeling of diseases originating within PR cell bodies (e.g., ER) and cilia may be modeled successfully and are not dependent/less dependent on the presence of RPE. The connecting cilium of photoreceptors is a very specialized structure providing stability for fragile and very compartmentalized photoreceptor OSs as well as enabling protein trafficking across the ISs between photoreceptor cell body and OSs (Pearring et al., 2013). Perturbing such protein traffic triggers photoreceptor cell death in many neurosensory ciliopathies, which involve not only vision but also hearing (Rachel et al., 2012a,b; Chen H.Y. et al., 2019). Photoreceptor disk formation is initiated at the level of cilia via specialized recently described mechanism of peripherin-dependent suppression of ciliary ectosome release (Salinas et al., 2017). The capture of photons and initiation of phototransduction takes place in the outer segments, which critically dependent on well-developed microvilli of apical RPE around them (Finnemann and Chang, 2008). RPE microvilli wrap around the tips of outer segments though do not reach the base of photoreceptor cilium (Marmor, 2013).

Interaction of photoreceptor OSs with microvilli of apical RPE is critical for phototransduction, retina-RPE adhesion, stability/homeostasis of photoreceptors and their OSs, and long-term sustaining of vision (Bazan, 2007; Goldberg et al., 2016; Kevany and Palczewski, 2010; Molday and Moritz, 2015; Palczewski, 2014; Wang and Kefalov, 2011). RPE supports photoreceptor function directly (via receptor-ligand mechanism) and indirectly (by secreting interphotoreceptor matrix, recycling 11-cis retinal for phototransduction etc.) (Bonilha et al., 2006; Finnemann and Chang, 2008; Sparrow et al., 2010). And, while models of photoransduction defects and perturbed OS renewal (all causing RD) (Lolley et al., 1994; Molday, 1998; Molday and Moritz, 2015; Petersen-Jones et al., 2018) clearly cannot be built in vitro until such $3 \mathrm{D}$ long-term co-culture is recreated in a dish, cilia formation and function seems to be recapitulated well enough in retinal organoids likely because it is not dependent directly on microvilli (Figure....) (Marmor, 2013). Therefore,

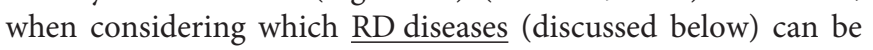
studied and modeled with retinal organoids, (some) ciliopathies 
may be an interesting and very important class of RD diseases (Chen H.Y. et al., 2019), which may be modeled even in the absence of RPE microvilli.

\section{Retinal Ganglion Cells}

Retinal ganglion cells are primarily affected in Glaucoma and other optic neuropathies and glaucoma, a leading cause of irreversible blindness in the United States and the world ${ }^{5}$. The main technological limitation of modeling glaucoma with retinal organoids is clearly the lack of the connecting partners of RGC neurons (visual centers in the brain). Yet, with the development of assembloids (retina-brain organoid co-cultures) technologies, this limitation seems to be only temporary.

The optic nerve originates in the retina and is formed by the axons of retinal ganglion cells (RGCs), the only type of retinal neurons, which requires long-distance connectivity (compared to other cell types, which use short distance connectivity: photoreceptor: bipolar neurons and INL neurons: RGCs). Modeling of RGC biology and disease in retinal organoids is challenged the need of RGCs to establish longdistance connectivity with visual centers in the brain to survive. RGC viability critically depends on their connectivity to visual cortex neurons, and such nerve fibers carry supportive (trophic) factors between RGCs and visual cortex neurons (Johnson et al., 2009). Damage to the optic nerve (e.g., the axotomy) can cause interruption or destruction of nerve cell connections and therefore, disrupt the flow of trophic factors leading to the gradual but steady loss of vision caused and RGC death. Restoration of trophic support (even partial) leads to preservation of RGCs (Mo et al., 2002; Nakazawa et al., 2002; van Adel et al., 2005). RGC layer will survive for months to years post injury as long as there is preservation of axonal connectivity between the RGC nerve fibers (forming the optic nerve) and the neurons of the visual cortex (Chang et al., 2006; Chang, 2013). One may find the retina in advanced degeneration stage (no photoreceptors and thin/degenerated INL) but with almost a normal RGC layer and optic nerve (Chang et al., 2002). However, it is feasible to study RGC development, organization and initial steps of axonal outgrowth to uncover factors promoting neurite elongation, guidance and target selection (Fligor et al., 2018). In the absence of their natural targets (visual centers in the brain) the RGC axons may grow randomly and even traverse the retina (Singh et al., 2015). With newly developed concept of retinabrain ("assembloids") co-culturing methods (Gopalakrishnan, 2019; Pacitti et al., 2019) retinal organoids are becoming a very promising model of optic nerve regeneration, reconnection of retina to brain (Kurimoto et al., 2010; de Lima et al., 2012; Erskine and Herrera, 2014; Crair and Mason, 2016; Benowitz et al., 2017; Laha et al., 2017) and potentially glaucoma [when the chambers for ocular pressure mimicking may be designed for recreating intraocular pressure homeostasis (Acott et al., 2014; Wu et al., 2019)] .

Collectively, these studies demonstrate that retinal organoids can be successfully differentiated from hiPSCs lines derived from retinal disease patients and used for delineating and modeling

${ }^{5}$ www.glaucoma.org complex disease mechanisms, closely recapitulating the featured of $\mathrm{RD}$ diseases in patients. This in turn makes them reliable models for drug discovery.

\section{Cell and Tissue Replacement Therapies for Retinal Degenerative Diseases}

Before the arrival of retinal organoid technology, the aborted human fetal tissue (Radtke et al., 2008; Seiler and Aramant, 2012) and retinal progenitors derived from hPSCs (Banin et al., 2006; Lamba et al., 2006; Hambright et al., 2012) (embryonic and induced) were the two cell sources for transplantation. Human fetal tissue is a gift, with strong ethical restrictions and limited supply (NCSL, 2008; NIH, 2009; Finklea et al., 2015; Gerrelli et al., 2015; Wadman, 2015). A very promising and pioneering work on fetal retinal tissue transplantation has been done by Drs. Seiler, Aramant and Radtke (Radtke et al., 2002, 2004, 2008; Seiler et al., 2010; Lin et al., 2018). As discussed above, retinal organoids provide unprecedented way of approaching basic and translational aspects of human retinal biology for disease modeling, drug screening and also as source of retinal cells and retinal tissue for subretinal transplantation aimed at treating blindness.

Age related macular degeneration and RP/LCA are very good and tempting diseases for evaluating retinal sheet replacement strategies with retinal organoids (Assawachananont et al., 2014; Shirai et al., 2016; Mandai et al., 2017a; McLelland et al., 2018; Tu et al., 2018). Though both types of diseases are good targets for such therapy, AMD is not a purely genetic disease and etiology is not completely elucidated, while most RPs are recessive and can be avoided in the near future with advanced genetic testing and genetic counseling. There are at least 15 million people in the US affected by AMD, with at least 2 million having an advanced AMD stage. Macular patch approach, depending on organoidderived photoreceptor sheet-RPE sheet coculture, is an attractive approach to bring vision to central retina. The size of human maculae is about $5 \mathrm{~mm}$ in diameter (Kolb, 2005), and biological retinal patch $\sim 4 \times 4$ or $5 \times 5$ millimeters $(\mathrm{mm})$ on a flat sheet of biomaterial carrier seems like a doable strategy (Ramsden et al., 2013; Mandai et al., 2017b; Kashani et al., 2018). It can be grafted to the back of patient's eye to bring a layer of healthy and functional retinal tissue to replace patient's own retina (too damaged/degenerated after the injury). This tissue is expected to reconnect (based on studies in mice) (Seiler et al., 2010, 2017) to patient's RGCs and function as a bioprosthetic device similar to completely electronic chips currently approved for clinic (e.g., Argus II Stronks and Dagnelie, 2014). However, due to biological nature and much higher pixel density (which is expected to bring better vision Mathieson et al., 2012), where each individual lightcapturing neuron [photoreceptor] of the patch is equal to a pixel, the biological retinal patch approach is expected to eventually supersede the electronic (neuroprosthetic) chip approach and to generate bioprosthetic retina capable of permanent integration into patient's globe. A large piece of tissue from a hESC-derived retinal organoid carrying a layer of PRs and second order neurons provides the light sensors that can synaptically transmit visual information to patient's RGCs, which persist even after all PRs are degenerated (Lin and Peng, 2013). Unlike electroprosthetic 
chips, a "bioprosthetic" implant based on hESC-derived retinal organoids enables long-lasting synaptic integration, and can be adjusted to carry more cones than rods (Mears et al., 2001) if the goal is to repair the macula. These technologies will be subject of intense studies in the next few years and will likely result in symbiosis of 2 approaches (biological and electronic) and neurobioprosthetic retinal implants, utilizing biomaterials and of course retinal organoids. Surgical technologies are already here to deliver such 3D constructs into the eye (Kashani et al., 2018).

CRISPR-Cas-9 gene correction in retinal organoids has been tested successfully in several human RD models (Deng et al., 2018; Huang et al., 2019; Lane et al., 2020) as well as in vivo in mice (with up to $45 \%$ efficiency of repair of dominant-negative Rho mutation to wild type allele in photoreceptors) (Li et al., 2018). CRISPR-Cas-9-based repair may be especially productive and needed for RP diseases, which are caused by dominantnegative mutations, and may potentially work together with retinal tissue replacement (discussed above).

\section{CURRENT LIMITATIONS OF RETINAL ORGANOID TECHNOLOGY}

The current key limitations of retinal organoids for modeling and treating $\mathrm{RD}$ diseases are the lack of vasculature, the lack of continuous layer of RPE around the organoids, gradual degeneration of RGC and then INL in mature organoid cultures, lack of the connecting partners for RGC axonal elongation (critical for glaucoma) and critically, lack of RPE-photoreceptor interaction (critical for dry AMD, RP and LCA). Here we discuss ongoing and future work needed to address these limitations.

\section{Absence of Vasculogenesis in Retinal Organoids}

The retina is one of the most energy-demanding tissues, with high need for oxygen and nutrients (Warburg, 1928; Ng et al., 2015; Sun and Smith, 2018). Adult retina generates energy via aerobic glycolysis, in addition to oxidative phosphorylation, to compensate for such high demand ( $\mathrm{Ng}$ et al., 2015) similar to cancer cells (Warburg et al., 1927; Vander Heiden et al., 2009). The oxygen and nutrient supply are delivered either from the choroid side (thus, RPE and photoreceptor layers are avascular and depend on choriocapillaris), or central retinal artery (which brings oxygen to RGC and INL; these 2 layers carry vascular capillaries). These energy demands are caused by energy-demanding phototransduction and related neurotransmitter demand caused by constant depolarization/repolarization (collectively: hyperactive neuronal activity) (Wong-Riley, 2010). However, the initial steps in retinal development lack vasculature (Hughes et al., 2000; McLeod et al., 2006; Hasegawa et al., 2008) (about week14), while the nutrition and oxygenation are delivered from choroid (beneath the RPE) and hyaloid (above the developing retina) (Ye et al., 2010) (Figure 5). This can be easily recreated in tissue culture incubator in smaller-size organoids, where penetration of oxygen and metabolites are not yet impacted much by organoid size. This indicates that initial stages of retinogenesis in a dish may be not impacted by lack of vasculature in organoids (i.e., neurovascular niche is not relevant at this stage, additionally confirming young organoids as a good model of early retinal development (Meyer et al., 2009)). Indeed, human fetal retina ( $\sim$ Carnegie stage 23 , day 56-60 and slightly older retina week 11-13) highly resemble human retinal organoids ( $\sim$ week 10 12), as $\mathrm{CHX} 10[+] \mathrm{NR}$ with multipotential retinal progenitors is gradually separating into outer and inner neuroblast layers (ONBL and INBL). There are differences in the dynamics of retinal vasculature development in humans versus mice, though it is not clear if this is relevant to retinal organoid culture. However, in humans vascular development is complete before birth, while in mice and rats vascular development takes place postnatally [discussed in Sun and Smith (2018)]. There is ongoing productive work to recreate choroid-RPE border in a dish, which is a step in the right direction toward building a complete "retina in a dish" model (Jha and Bharti, 2015; Song and Bharti, 2016) from retinal organoids, RPE sheets and biomaterials. In general, organoid vascularization is a very active research niche at the moment (Grebenyuk and Ranga, 2019) since the initial stages (organoid formation) has been worked out. However, because of the clear differences between the laminated and heavily vascularized structure of human inner retina and spheroid "closed" and avascular structure of retinal organoids, where the oxygen and nutrition supply have difficulty penetrating into the INL/RGC layers (closer to the organoid core (Capowski et al., 2019)), it seems so far impossible to maintain the long-term dynamics of development in retinal organoids, shaped as a sphere. As a result, a number of labs, including ours, noted the almost exclusive survival of photoreceptors in the ONL and gradual demise of INL and RGCs in the organoid core (Wahlin et al., 2017; Capowski et al., 2019), highlighting older retinal organoids (maintained with current level of technology) as a questionable models for a number of RD conditions. Hypoxia inducible factor 1 (HIF1) plays an important role in response of retina to oxygen level (hypoxic conditions), specifically alpha (HIF-1 $\alpha$ ) subunit, which becomes stable and translocates to the nucleus only in hypoxic conditions (Hughes et al., 2010). There is constitutive HIF-1a signaling reported in the normal rat and human retina suggesting an important physiological role (Hughes et al., 2010). The level of HIF-1a is high in both developing human fetal retina and young and mature (6-month-old) retinal organoids (based on RNA-Seq data sets from various publications). Because hypoxic conditions and active HIF-1a were reportedly noted as important for tissue regeneration (Nauta et al., 2014; Zhang et al., 2015; Heber-Katz, 2017; Lee et al., 2019), retinal organoids may be an interesting model for exploring retinal tissue (specifically photoreceptor) regeneration by modulating HIF-1a pathway, active in organoids.

\section{LACK OF RPE PHOTORECEPTOR INTERACTION IN RETINAL ORGANOIDS}

Retinal organoids do not have the continuous layer of RPE around the organoids (Figure 6). Achieving photoreceptor-RPE interaction and designing a functional subretinal niche in retinal 

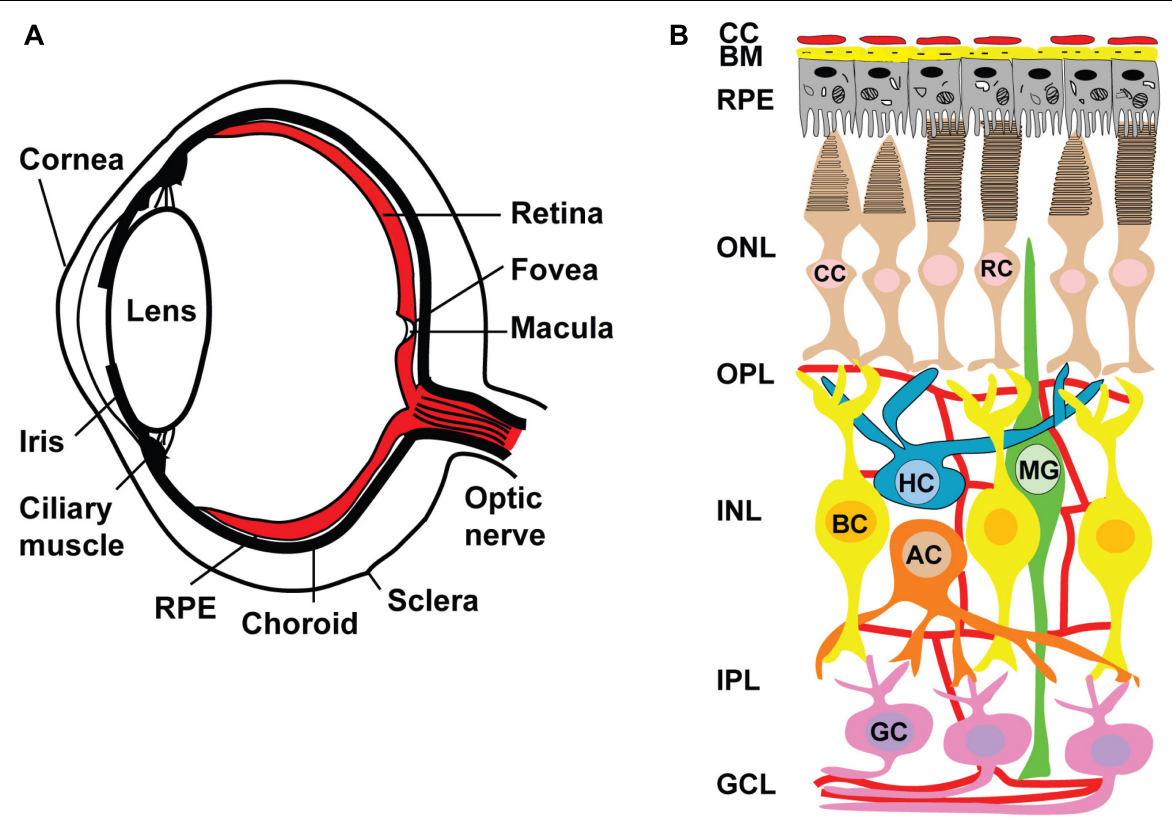

FIGURE 5 | Anatomy of human eye and retinal circuits. (A) Schematic drawing of a cross-section through human eye. Light enters the eye through the cornea, passes through the pupil, lens and strikes the retina. Retina is the light-sensitive tissue lining the inner surface of the eye. Visual information from retina transmits to the brain through optic nerve fiber. In the middle of the retina small depression is called the fovea and is responsible for high resolution vision. Region surrounding the fovea is called as macula and are rich in only cones. Retinal pigment epithelium (RPE) is a pigmented layer and separates the choroidal blood supply from the photoreceptors. Choroid is a vascular layer of the eye. The sclera is a tough white sheath around the outside of the eyeball. (B) Schematic diagram of normal retina circuits. Mammalian retina consists of six major types of neuronal cells - rod (RC) and cone (CC) photoreceptors also horizontal (HC), bipolar (BC), amacrine (AC) and retinal ganglion cell (RGC). The Muller cell are the glial cells that span across the retina and their somata. RPE provides metabolic and transport functions essential for homeostasis of the neural retina. Bruch's membrane (BM) is a highly specialized and multi-laminar structure in our retinas that forms the basis for mediating interactions between the retinal pigment epithelium and blood flow from the choroid. Choroidal capillaries (CC) are the blood capillaries present in choroid that supply oxygen and nourishment to the outer layer of the retina. Retinal blood vessels are present in OPL, IPL and RGC layers.

organoids is an urgent goal critically needed for designing better models of human retina for drug development and for tissue replacement. As photoreceptors develop their specialized structure adapted for phototransduction, they elongate the inner and outer segments (ISs and OSs) into microvilli, elongating in sync on the apical RPE side (Figure 7). This elongation process takes place rapidly in developing mouse eye between approximately postnatal day 9.5 and 14.5 (Nasonkin et al., 2013), while in human developing retina the process starts in the $3^{\text {rd }}$ trimester and continues into infancy (Hendrickson et al., 2008). This indicates that to achieve outer segment elongation in human retinal organoid cultures one needs to wait approximately 24 weeks after the formation of retinal organoid, and 32 weeks or more to have OSs reach the maximum length, assuming that the organoid culture faithfully recapitulates human retinal development, and RPE-organoid co-culture system is established. Genetic ablation of RPE leads to complete loss of photoreceptor OSs (Longbottom et al., 2009), while hypoplastic changes in the apical RPE prevent OS elongation (Nasonkin et al., 2013), collectively pointing to the instructive and important role of RPE in outer segment elongation and maintenance. The interdigitation of OSs of photoreceptors and microvilli of apical RPE creates a stable NR-RPE border and a very specialized subretinal niche (absent or mostly absent in retinal organoids), where critical first steps of phototransduction take place in photoreceptor outer segments (Molday, 1998; Kefalov, 2012; Wang et al., 2009).

Photoreceptors have very compartmentalized structure adapted for phototransduction, which is supported by RPE microvilli (Molday and Moritz, 2015) (Figure 7). A number of extracellular ("interphotoreceptor") cell matrix (ECM) proteins important and some critical for phototransduction and photoreceptor OS maintenance reside in the ECM matrix surrounding photoreceptor OSs and apical RPE microvilli (Bonilha et al., 2006; Ebrahimi et al., 2014; Ishikawa et al., 2015; Kelley et al., 2015; Salido and Ramamurthy, 2019). One of them is Interphotoreceptor Retinol-Binding Protein (IRBP), which plays a very important role of shuttling 11-cis retinal from RPE cells and bleached pigment (all-trans retinol) from photoreceptors to RPE (Figure 7) (Jin et al., 2009). IRBP message is abundant in human retinal organoids (based on published RNA-Seq data from various labs). A number of other interphotoreceptor proteins were highlighted in recent publications, some focused on studying these proteins specifically in retinal organoids (Felemban et al., 2018; Salido and Ramamurthy, 2019). There is a lot of interest now in these proteins among the teams, trying to use retinal organoids for modeling of retinal diseases and for cell replacement therapies (Dorgau et al., 2019; Guo et al., 2019). This interest is guided by the expectations that 

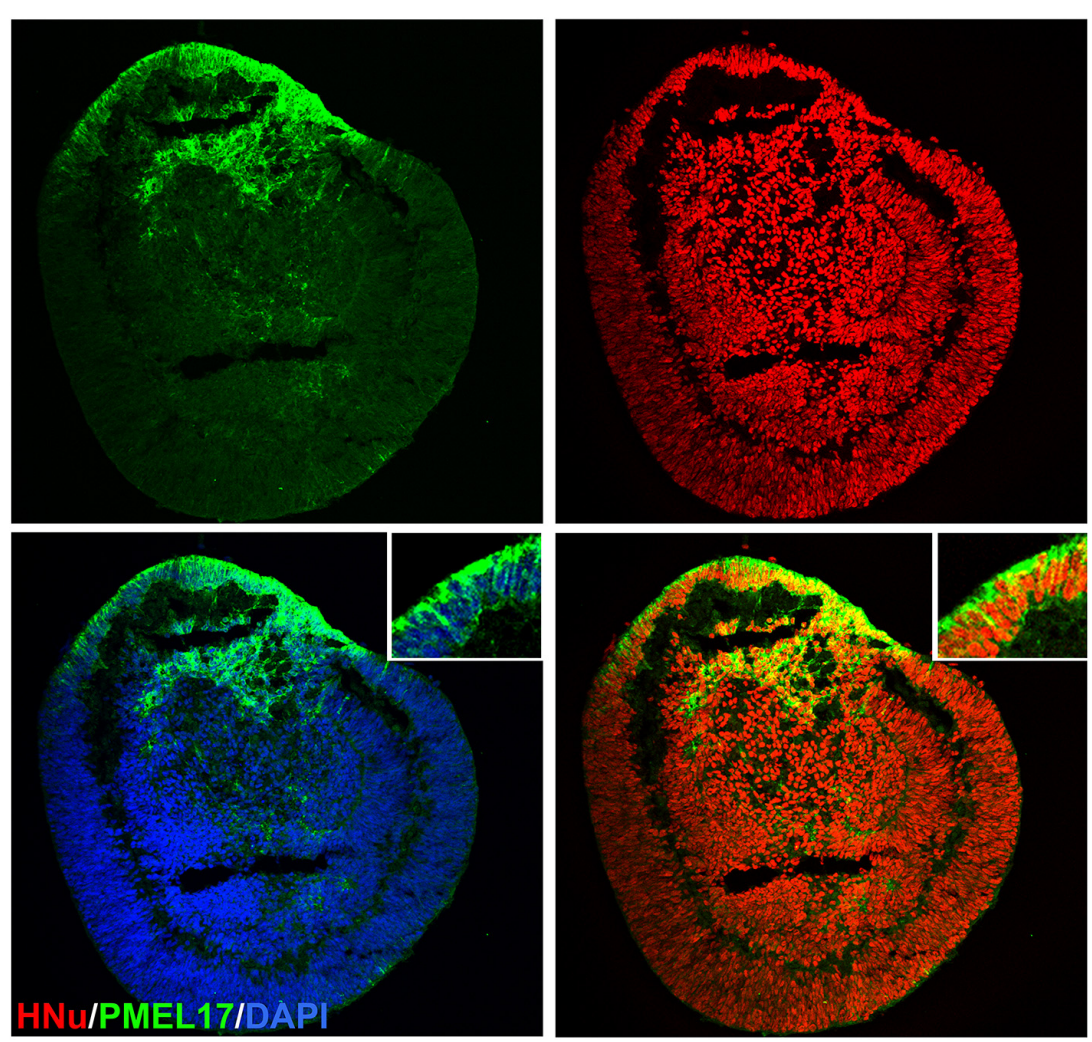

FIGURE 6 | Localization of PMEL17 in the retinal organoid. Immunostaining the retinal organoid (day 70) with pigmented RPE marker PMEL17 show patches of retinal organoids were pigmented. HNu stains the human nuclei. The insets in panel a are high magnification of area marked with asterisk (*). DAPI counter stains nuclei.

these "missing factors" (interphotoreceptor matrix proteins being some of them (Salido and Ramamurthy, 2019)) may help to build connectivity between RPE and photoreceptors in the organoids co-cultured with RPE in vitro to improve long-term culture of organoids and recapitulate the biology and structure of RPE-photoreceptor OS niche for disease modeling, drug screening and cell/tissue replacement therapies (Felemban et al., 2018; Achberger et al., 2019).

\section{Lack of Photoreceptor Disk Morphogenesis, Outer Segment Shedding, Phagocytosis in Retinal Organoids}

These processes are fundamental to photoreceptor biology and phototransduction, and are critically missing in organoids (so far), thus reducing our ability to model many retinal degenerative diseases in a dish. Disk shedding occurs on the distal side of OSs facing the RPE, and these disks are phagocytosed by RPE, while disk morphogenesis takes place at the base of the OSs (next to the cilium) (Kolb, 1995; Molday and Moritz, 2015; Volland et al., 2015b). Up to $10 \%$ of OS discs are renewed daily (Young, 1967). The stack of rod photoreceptor OSs consists of over 1000 compact disk structures in adult retina (Molday and Moritz, 2015). However, the maximum number of disks we and others observed in the retinal organoids cultured for 68 months is limited to several disks, and these are not typically organized tightly in a stack (Wahlin et al., 2017; Nasonkin et al., 2019). However, some in vivo results reveal better organization of OSs and longer OSs in the long-term subretinal grafts (Shirai et al., 2016), all pointing toward the lumen of rosette-like photoreceptor aggregates in subretinal space (Shirai et al., 2016; Nasonkin et al., 2019). Naturally, there is no ongoing renewal and phagocytosis processes in long term retinal cell and retinal organoid cultures, but it has been expected for a long while that with developing photoreceptor-RPE co-culture systems faithfully recapitulating structure and function of the subretinal niche, OS elongation and photoreceptor-RPE biology can be reestablished (German et al., 2008; Di Lauro et al., 2016; DiStefano et al., 2018; Akhtar et al., 2019; Brooks et al., 2019; Capowski et al., 2019). As work on retinal repair rapidly progresses (Holmes, 2018a,b; Makin, 2019), these technologies will likely be developed in the next 3-5 years as a cheaper and robust model for drug screening and discovery, as well as platform for biomanufacturing $3 \mathrm{D}$ retinal tissue transplants to repair vision in advanced $\mathrm{RD}$ patients.

\section{The Visual Cycle}

The visual cycle in mammalian retina (and lack of visual cycle in retinal organoids) Photoreceptors convert lights into an electrical signal that pass through the second and third 


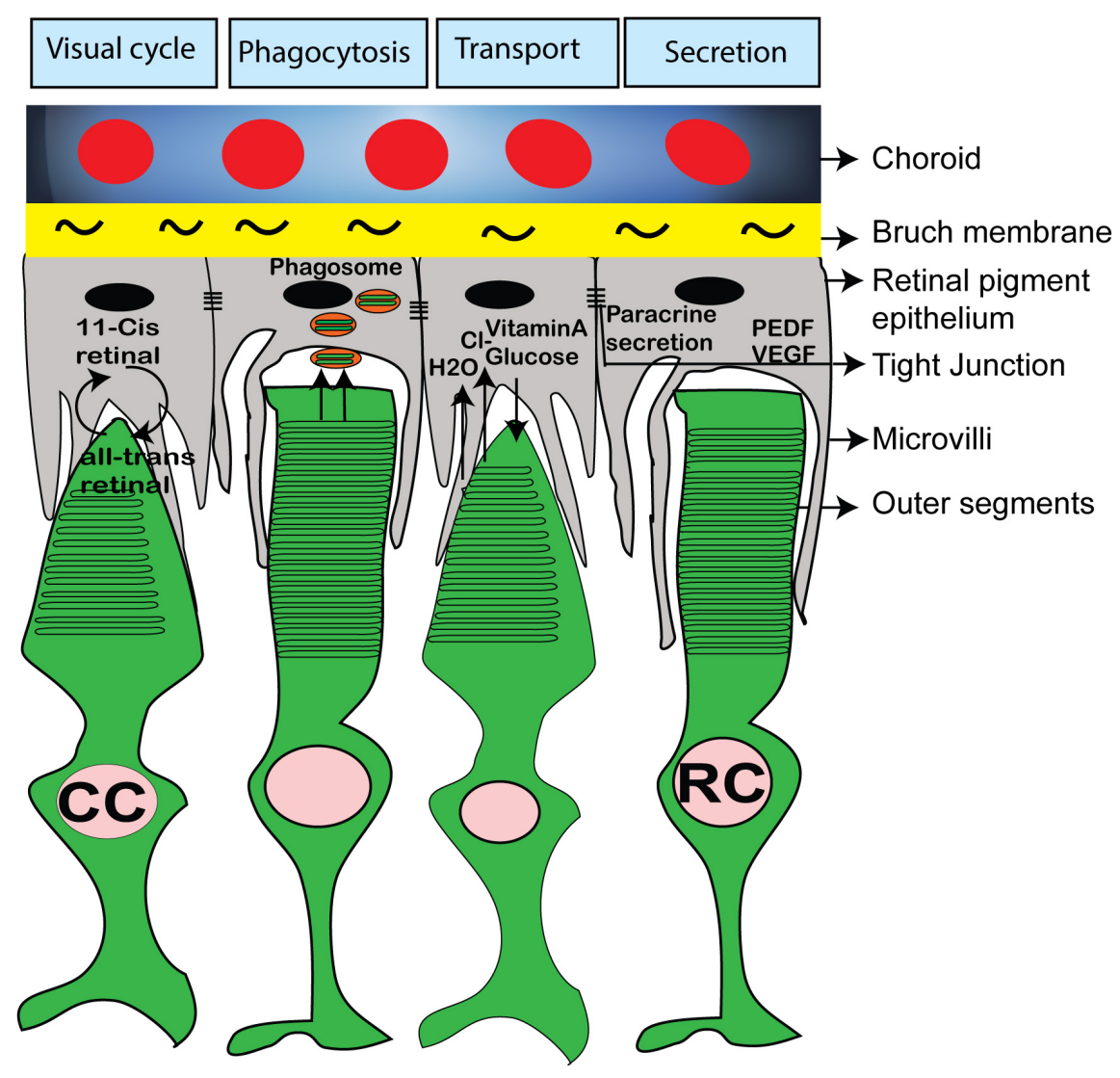

FIGURE 7 | Schematic diagram showing important functions of RPE and its interaction with rod and cone photoreceptor outer segments. The RPE microvili interacts with photoreceptor OS and RPE cells are involved in visual cycle, phagocytosis of outer segments disc, nutrient uptake and paracrine secretion of PEDF, VEGF.

layer of retinal neurons and conveys the information to the brain. Defect in RPE cell or photoreceptor cell impairs the visual function and causes retinal blinding diseases (Age related macular degeneration, Retinitis pigmentosa, Leber congenital amaurosis). The biochemistry of visual cycle has been worked out in seminal work of many laboratories (Hsu and Molday, 1993; Pugh and Lamb, 1993; Baehr and Palczewski, 2007; Luo et al., 2008; Arshavsky and Burns, 2012; Palczewski, 2014). Clearly, no similar Ca(2+) or cGMP gradients (which are present in the subretinal niche) are present in developing retinal organoids though increased level of $\mathrm{Na}^{+}, \mathrm{K}^{+}$and $\mathrm{Ca}^{2+}$ electric current are present in developing organoids (Singh et al., 2015). This could be one of many factors causing gradual degeneration of photoreceptors in long-term organoid cultures. It is expected that recreation of photoreceptor-RPE niche in a dish would make it possible to substantially increase the viability of photoreceptors in long-term in vitro cultures (Di Lauro et al., 2016; Achberger et al., 2019; Akhtar et al., 2019; Chen Y. et al., 2019), thus enabling disease modeling and drug screening of diseases, where the integrity of subretinal niche and photoreceptor-RPE structural and functional connectivity is of paramount importance for maintaining visual function.

\section{1-cis Retinal}

11-cis retinal is critical for visual process in the OSs and OSs do not have it if we don't have RPE. In the RPE65 mutant dogs a lack of 11-cis retinal supply to the photoreceptors leads to very reduced function of both rods and cones (Gearhart et al., 2008) similar to that observed in RPE65-mutant mice (Redmond et al., 1998). RPE is critically important for maintaining visual function (Strauss, 2005; Bharti et al., 2006, 2011) and recycles retinal between photoreceptors and RPE (11-cis -alltrans retinal). Though 11-cis retinal (or, more stable for of it, 9-cis form of retinal (Fan et al., 2003)) can be provided in trans to enhance visual responses (Gearhart et al., 2010), this will not substitute for OS homeostasis, turnover and recycling in photoreceptor sheets from organoids and RPE sheets (as discussed above) unless the subretinal niche with close OS-microvilli interaction will be recreated in a dish. After all, though hESC- and hiPSC-derived RPE sheets can indeed phagocytose photoreceptor OSs (Carr et al., 2009; Idelson et al., 2009; Bharti et al., 2011) (one of many functions of RPE in subretinal niche (Mazzoni et al., 2014)), OSs start degenerate pretty quickly after retinal detachment unless physical reattachment takes place quickly, within a day or less (Fisher and Lewis, 2010). Retinal detachment negatively impacts the biological process of disk production and disk shedding. Though 
OS-specific proteins are synthesized, they start to localize to locations other than OSs: Opsin accumulates in the plasma membrane, Peripherin/rds appears in cytoplasmic vesicles. It was reported that proteins specific to cone OSs are more sensitive to OS damage, and after only one week of cone opsin mislocatization the expression of cone opsins is downregulated. It was noted that within 24 to $72 \mathrm{~h}$ after retinal detachment almost all rod and cone OSs display signs of OS degeneration: they are shorter, acquire abnormal morphology with disks not positioned as stacks (Fisher and Lewis, 2006; Wickham et al., 2013). These features of OS morphology are very similar to those observed by our lab and others in long-term cultures of human pluripotent stem cells (hPSC)-retinal organoids (Wahlin et al., 2017; Capowski et al., 2019; Nasonkin et al., 2019). severely shortened but yet visible OSs can persist for up to several weeks after retinal detachment (Fisher and Lewis, 2006; Wickham et al., 2013).

\section{Variability in Size, Shape, Photoreceptor Density, Lamination}

Variability in size, shape, photoreceptor density, lamination determined by cell line-specific and protocol-specific differences (both derivation and maintenance) were described and documented (Capowski et al., 2019; Cowan et al., 2019; Mellough et al., 2019). However, it is feasible even with current technologies to culture and maintain organoids for longer than one year, as a proof-of-principle (Capowski et al., 2019). It quickly became evident that once the self-formation of retinal organoids is done (which can be achieved with a number of protocols maintaining and promoting the propensity of retina (the outpocketing of anterior neuroectoderm) to form, further maturation and long-term maintenance of retina-ina-dish requires more sophisticated media providing more salts, anti-oxidants, a milieu of supporting paracrine factors (provided by serum or serum plus RPE conditioned medium), etc. (Zhong et al., 2014; Bardy et al., 2015; Singh et al., 2015; Di Lauro et al., 2016; Achberger et al., 2019; Akhtar et al., 2019; Capowski et al., 2019). These issues are mostly technical, and current biomanufacturing technologies allow generating large number of aggregates of a defined size (e.g., for large-scale drug discovery) if needed.

\section{SUMMARY}

Modeling early retinal development with hESC and hiPSC approaches (from eye field determination and before photoreceptor develop outer segments) seems the most straightforward and very productive way of using retinal organoids for basic and translational research (Meyer et al., 2009). With arrival of methods of co-culturing between brain and retinal organoids (assembloids (Gopalakrishnan, 2019)), engineering vascularization of organoids (Grebenyuk and Ranga, 2019) and developing pressurized chambers (for glaucoma studies, all discussed above) it will become feasible, and very soon, to use human retinal organoids for studying wet AMD and glaucoma and developing better drugs tested in models faithfully representing pathophysiology of these diseases.

\section{Conceptual Efforts}

Conceptual efforts should be centered on better understanding of rebuilding PR-RPE niche with cells and layers of tissue

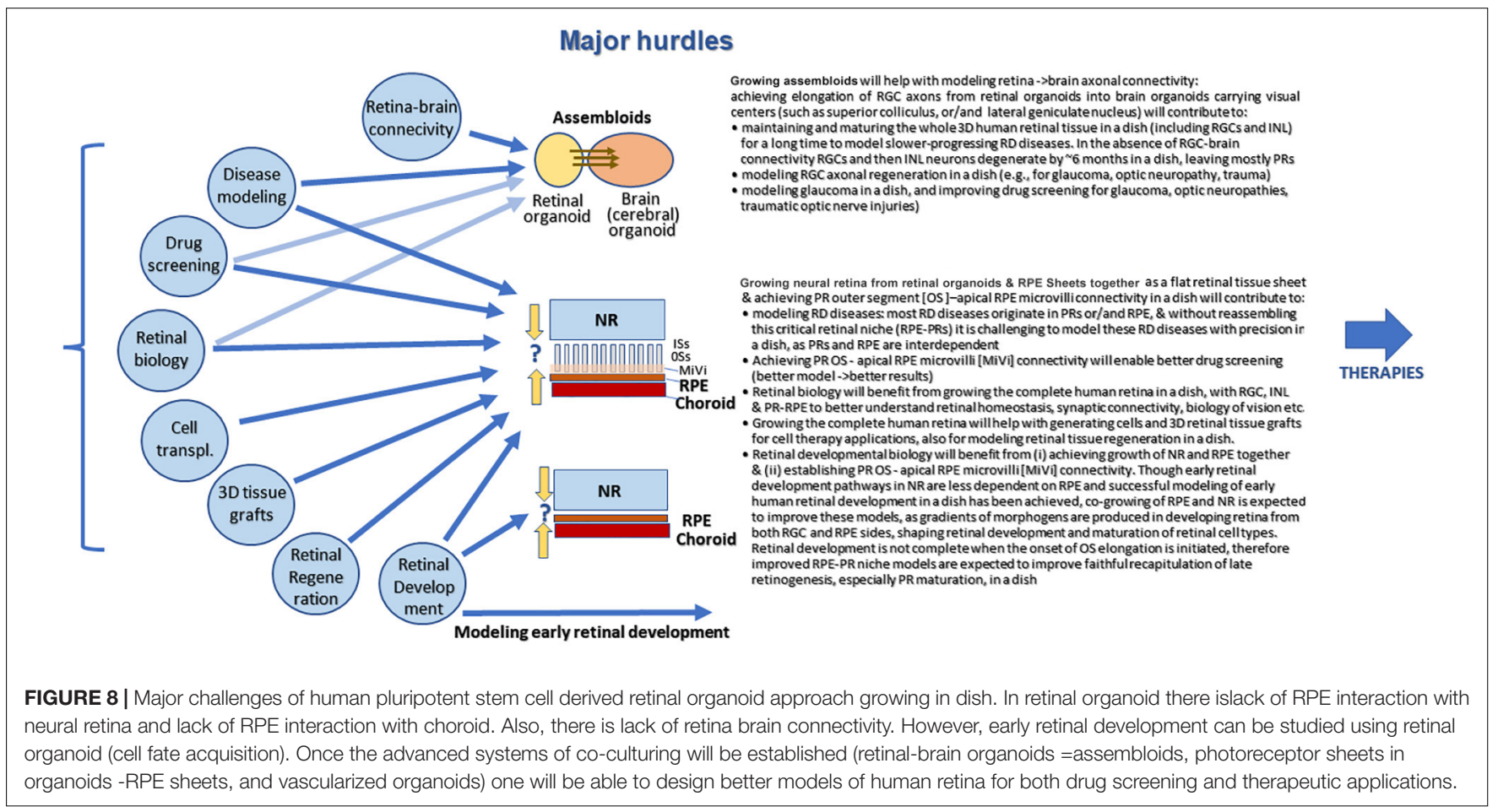


(e.g., PR layer and RPE sheet), building models of AMD and glaucoma with functional PR-RPE niche, developing techniques for designing cone photoreceptor-only sheets with RPE for modeling of human macula, generating retinabrain organoids co-culture methods for studying and treating glaucoma, and (potentially) investigating vascularization of hESC-retina in a dish. This will open the door for multiple therapeutic/translational approaches (drug testing, photoreceptor transplantation, 3D retinal tissue transplantation). 3D human retinal tissue model on a chip is still unattainable but technologies are being developed to make this a reality in the next 5-7 years (McUsic et al., 2012; Gu et al., 2018; Achberger et al., 2019; Haderspeck et al., 2019; Masaeli et al., 2020). Big Pharma companies need this tool to do largescale screening of drugs to suppress/ameliorate RD. This screening is not possible with mouse models (not human, expensive, cannot be scaled up) and not productive in cultured retinal cells.Most cells in primary retinal culture are represented by Muller glia after 2-3 several passages; immortalized cell lines have multiple changes in signaling pathways, lack of cell-cell connectivity and loss of many feature of retinal biology, critically needed to faithfully recapitulate pathology.

\section{Among Current Limitations}

Among current limitations one can list lack of functional maturation of PRs caused by lack of PR-RPE niche, premature degeneration, gradual loss of RGCs and second order neurons (Figure 8) and lack of connecting targets for RGCs to elongate and project. Difficulty for large-scale isolation of "good" retinal organoids and standardization of retinal organoid size and shape are also limitations yet it is expected that progress in biomanufacturing and biologic product development will soon be able to solve these hurdles.

\section{RPE-PR Interaction}

RPE-PR interaction: (and lack of -in organoids) This hurdle is clearly biology-driven but the general expectation is that it could be circumvented with progress in technology, as organoid-biomaterial work progresses. Interestingly, even without RPE small stubby outer segments with rudimentary stacks of disks still grow, and in some cases even elongate, yet fail to develop organized stacks of outer segments, likely due to the absence of RPE-photoreceptor interaction. This interaction may be an inducing factor of elongation and most likely a stabilizing factor for disk formation. Equally interesting is the fact that there is hardly any data demonstrating the interaction between RPE and photoreceptors and elongation of outer segments in a dish, even in long-term organoid cultures.

The RPE layer is normally expected to polarize into apical and basal sides, and establish a network of microvilli on the apical side, interacting with photoreceptors and nurturing photoreceptor outer segments. Retinal organoids, however, normally carry patches of RPE on one side, thus directly exposing photoreceptors in the developing organoids to neural medium. Recreation of the critical retinal niche on the border between the apical RPE and photoreceptors, where many retinal disease mechanisms originate, is so far unattainable and is a focus of investigation in many labs. Interestingly, even without RPE small stubby outer segments with rudimentary stacks of disks still grow, and in some cases even elongate, yet fail to develop organized stacks of outer segments, likely due to the absence of RPEphotoreceptor interaction. This interaction may be an inducing factor of elongation and most likely a stabilizing factor for disk formation. Equally interesting is the fact that there is hardly any data demonstrating the interaction between RPE and photoreceptors and elongation of outer segments in a dish, even in long-term organoid cultures. Though the expectations are that the translational research in the near future may solve this hurdle (which is clearly biology-driven but could be clearly improved as organoid-biomaterial work progresses), so far the absence of this RPE-photoreceptor niche imposes clear limitations on both modeling/drug screening and transplantation approaches, especially for AMD/human macula work. Here we dissected the different retinal degenerative diseases and organoid technologies and present our thinking how and where retinal organoid technology can contribute the most to developing therapies even with a current limitation and absence of outer segments, elongating into the microvilli of RPE. Understanding how PR and RPE come together to rebuild functional subretinal niche is important not only for tissue transplantation and modeling of long-term $\mathrm{RD}$ disease in a dish, but also for promising cell therapy approaches, based on sorted photoreceptor transplantation (Singh et al., 2013; Gagliardi et al., 2018; Lakowski et al., 2018) (which is more feasible technically that grafting tissue (Seiler and Aramant, 2012) yet needs better understanding of biology to rebuild PRRPE border with inner and outer segments). Photoreceptor (sorted $\mathrm{CD} 73[+]$ cell suspension) transplantation so far has to depend on approaches circumventing this biological question like optogenetically engineered photoreceptors (GaritaHernandez et al., 2019), where functional OSs, where light it converted to electricity are replaced by optogenetic constructs, mimicking OS function.

Now it is very interesting time in translational biology combining pluripotent stem cell technologies, biomaterials, 3D organoid and co-culture approaches in effort to model, rebuild in a dish and transplant the complex 3-dimensional tissue - the retina. This exciting time can be compared to the time when scientists were searching for elusive ways to dedifferentiate adult human cells back to pluripotent state. Developing 3D co-culture technology faithfully recapitulating the biology and physiology of the subretinal niche, together with organoid vascularization strategies, will open the new opportunities for designing better disease modeling in a dish to study the "late-onset" retinal diseases, which impact visual function at the lever of OS:RPE. In additional to biological breakthrough, this will be an ethical breakthrough, enabling us to avoid using animals excessively for studying development and treating diseases. 


\section{AUTHOR CONTRIBUTIONS}

RS conceptualized the review, generated the data, and wrote the manuscript. IN conceptualized the review, processed the data, and wrote the manuscript.

\section{REFERENCES}

Aasen, D. M., and Vergara, M. N. (2020). New drug discovery paradigms for retinal diseases: a focus on retinal organoids. J. Ocul. Pharmacol. Ther. 36, 18-24. doi: 10.1089/jop.2018.0140

Abramov, I., Gordon, J., Hendrickson, A., Hainline, L., Dobson, V., and LaBossiere, E. (1982). The retina of the newborn human infant. Science 217, 265-267. doi: 10.1126/science.6178160

Achberger, K., Probst, C., Haderspeck, J., Bolz, S., Rogal, J., Chuchuy, J., et al. (2019). Merging organoid and organ-on-a-chip technology to generate complex multi-layer tissue models in a human retina-on-a-chip platform. Elife 8:e46188.

Acott, T. S., Kelley, M. J., Keller, K. E., Vranka, J. A., Abu-Hassan, D. W., Li, X., et al. (2014). Intraocular pressure homeostasis: maintaining balance in a highpressure environment. J. Ocul. Pharmacol. Ther. 30, 94-101. doi: 10.1089/jop. 2013.0185

Adler, R., and Canto-Soler, M. V. (2007). Molecular mechanisms of optic vesicle development: complexities, ambiguities and controversies. Dev. Biol. 305, 1-13. doi: 10.1016/j.ydbio.2007.01.045

Akhtar, T., Xie, H., Khan, M. I., Zhao, H., Bao, J., Zhang, M., et al. (2019). Accelerated photoreceptor differentiation of hiPSC-derived retinal organoids by contact co-culture with retinal pigment epithelium. Stem Cell Res. 39:101491. doi: 10.1016/j.scr.2019.101491

Akiyama, G., Sakai, T., Kuno, N., Kimura, E., Okano, K., Kohno, H., et al. (2012). Photoreceptor rescue of pigment epithelium-derived factor-impregnated nanoparticles in Royal College of Surgeons rats. Mol. Vis. 18, 3079-3086.

Androutsellis-Theotokis, A., Leker, R. R., Soldner, F., Hoeppner, D. J., Ravin, R., Poser, S. W., et al. (2006). Notch signalling regulates stem cell numbers in vitro and in vivo. Nature 442, 823-826. doi: 10.1038/nature04940

Arroba, A. I., Wallace, D., Mackey, A., de la Rosa, E. J., and Cotter, T. G. (2009). IGF-I maintains calpastatin expression and attenuates apoptosis in several models of photoreceptor cell death. Eur. J. Neurosci. 30, 975-986. doi: 10.1111/ j.1460-9568.2009.06902.x

Arshavsky, V. Y., and Burns, M. E. (2012). Photoreceptor signaling: supporting vision across a wide range of light intensities. J. Biol. Chem. 287, 1620-1626. doi: 10.1074/jbc.r111.305243

Assawachananont, J., Mandai, M., Okamoto, S., Yamada, C., Eiraku, M., Yonemura, S., et al. (2014). Transplantation of embryonic and induced pluripotent stem cell-derived 3D retinal sheets into retinal degenerative mice. Stem Cell Rep. 2, 662-674. doi: 10.1016/j.stemcr.2014.03.011

Baehr, W., and Palczewski, K. (2007). Guanylate cyclase-activating proteins and retina disease. Subcell. Biochem. 45, 71-91. doi: 10.1007/978-1-4020-6191-2_4

Bangs, F., and Anderson, K. V. (2017). primary cilia and mammalian Hedgehog signaling. Cold Spring Harb. Perspect. Biol. 9:a028175. doi: 10.1101/cshperspect. a028175

Banin, E., Obolensky, A., Idelson, M., Hemo, I., Reinhardtz, E., Pikarsky, E., et al. (2006). Retinal incorporation and differentiation of neural precursors derived from human embryonic stem cells. Stem Cells 24, 246-257. doi: 10.1634/ stemcells.2005-0009

Bardy, C., van den Hurk, M., Eames, T., Marchand, C., Hernandez, R. V., Kellogg, M., et al. (2015). Neuronal medium that supports basic synaptic functions and activity of human neurons in vitro. Proc. Natl. Acad. Sci. U.S.A. 112, E2725-E2734.

Barnstable, C. J., and Drager, U. C. (1984). Thy-1 antigen: a ganglion cell specific marker in rodent retina. Neuroscience 11, 847-855. doi: 10.1016/0306-4522(84) 90195-7

Bassett, E. A., and Wallace, V. A. (2012). Cell fate determination in the vertebrate retina. Trends Neurosci. 35, 565-573. doi: 10.1016/j.tins.2012.05.004

Bazan, N. G. (2007). Homeostatic regulation of photoreceptor cell integrity: significance of the potent mediator neuroprotectin D1 biosynthesized from

\section{FUNDING}

The work was supported by National Eye Institute (NIH) Grants 5R44EY027654-01, 5R44EY027654-02, and 3 R44 EY 027654-02 S1.

docosahexaenoic acid: the Proctor Lecture. Invest. Ophthalmol. Vis. Sci. 48, 4866-4881; biography 4864-4865.

Benowitz, L. I., He, Z., and Goldberg, J. L. (2017). Reaching the brain: advances in optic nerve regeneration. Exp. Neurol. 287, 365-373. doi: 10.1016/j.expneurol. 2015.12.015

Bharti, K., Gasper, M., Ou, J., Brucato, M., Clore-Gronenborn, K., Pickel, J., et al. (2012). A regulatory loop involving PAX6, MITF, and WNT signaling controls retinal pigment epithelium development. PLoS Genet. 8:e1002757. doi: 10.1371/ journal.pgen.1002757

Bharti, K., Miller, S. S., and Arnheiter, H. (2011). The new paradigm: retinal pigment epithelium cells generated from embryonic or induced pluripotent stem cells. Pigment Cell Melanoma Res. 24, 21-34. doi: 10.1111/j.1755-148x. 2010.00772.x

Bharti, K., Nguyen, M. T., Skuntz, S., Bertuzzi, S., and Arnheiter, H. (2006). The other pigment cell: specification and development of the pigmented epithelium of the vertebrate eye. Pigment Cell Res. 19, 380-394. doi: 10.1111/j.1600-0749. 2006.00318.x

Bird, A. C., Bressler, N. M., Bressler, S. B., Chisholm, I. H., Coscas, G., Davis, M. D., et al. (1995). An international classification and grading system for age-related maculopathy and age-related macular degeneration. The International ARM Epidemiological Study Group. Surv. Ophthalmol. 39, 367-374. doi: 10.1016/ s0039-6257(05)80092-x

Bonilha, V. L., Rayborn, M. E., Bhattacharya, S. K., Gu, X., Crabb, J. S., Crabb, J. W., et al. (2006). The retinal pigment epithelium apical microvilli and retinal function. Adv. Exp. Med. Biol. 572, 519-524. doi: 10.1007/0-387-32442-9_72

Brooks, M. J., Chen, H. Y., Kelley, R. A., Mondal, A. K., Nagashima, K., De Val, N., et al. (2019). Improved retinal organoid differentiation by modulating signaling pathways revealed by comparative transcriptome analyses with development in vivo. Stem Cell Rep. 13, 891-905. doi: 10.1016/j.stemcr.2019.09.009

Burnett, J. B., Lupu, F. I., and Eggenschwiler, J. T. (2017). Proper ciliary assembly is critical for restricting Hedgehog signaling during early eye development in mice. Dev. Biol. 430, 32-40. doi: 10.1016/j.ydbio.2017.07.012

Cai, Z., Feng, G. S., and Zhang, X. (2010). Temporal requirement of the protein tyrosine phosphatase Shp2 in establishing the neuronal fate in early retinal development. J. Neurosci. 30, 4110-4119. doi: 10.1523/jneurosci.4364-09. 2010

Capowski, E. E., Samimi, K., Mayerl, S. J., Phillips, M. J., Pinilla, I., Howden, S. E., et al. (2019). Reproducibility and staging of 3D human retinal organoids across multiple pluripotent stem cell lines. Development 146:dev171686. doi: 10.1242/dev.171686

Capowski, E. E., Wright, L. S., Liang, K., Phillips, M. J., Wallace, K., Petelinsek, A., et al. (2016). Regulation of WNT signaling by VSX2 during optic vesicle patterning in human induced pluripotent stem cells. Stem Cells 34, 2625-2634. doi: 10.1002/stem.2414

Carr, A. J., Vugler, A., Lawrence, J., Chen, L. L., Ahmado, A., Chen, F. K., et al. (2009). Molecular characterization and functional analysis of phagocytosis by human embryonic stem cell-derived RPE cells using a novel human retinal assay. Mol. Vis. 15, 283-295.

Cayouette, M., Poggi, L., and Harris, W. A. (2006). Lineage in the vertebrate retina. Trends Neurosci. 29, 563-570. doi: 10.1016/j.tins.2006.08.003

Chang, B. (2013). Mouse models for studies of retinal degeneration and diseases. Methods Mol. Biol. 935, 27-39. doi: 10.1007/978-1-62703-080-9_2

Chang, B., Hawes, N. L., Hurd, R. E., Davisson, M. T., Nusinowitz, S., and Heckenlively, J. R. (2002). Retinal degeneration mutants in the mouse. Vis. Res 42, 517-525. doi: 10.1016/s0042-6989(01)00146-8

Chang, B., Khanna, H., Hawes, N., Jimeno, D., He, S., Lillo, C., et al. (2006). Inframe deletion in a novel centrosomal/ciliary protein CEP290/NPHP6 perturbs its interaction with RPGR and results in early-onset retinal degeneration in the rd16 mouse. Hum. Mol. Genet. 15, 1847-1857. doi: 10.1093/hmg/ ddl107 
Chao, J. R., Lamba, D. A., Klesert, T. R., Torre, A., Hoshino, A., Taylor, R. J., et al. (2017). Transplantation of human embryonic stem cell-derived retinal cells into the subretinal space of a non-human primate. Transl. Vis. Sci. Technol. 6:4. doi: $10.1167 /$ tvst.6.3.4

Chen, H. Y., Welby, E., Li, T., and Swaroop, A. (2019). Retinal disease in ciliopathies: recent advances with a focus on stem cell-based therapies. Transl. Sci. Rare Dis. 4, 97-115. doi: 10.3233/trd-190038

Chen, M., Tian, S., Glasgow, N. G., Gibson, G., Yang, X., Shiber, C. E., et al. (2015). $\operatorname{Lgr} 5(+)$ amacrine cells possess regenerative potential in the retina of adult mice. Aging Cell 14, 635-643. doi: 10.1111/acel.12346

Chen, S., Li, H., Gaudenz, K., Paulson, A., Guo, F., Trimble, R., et al. (2013). Defective FGF signaling causes coloboma formation and disrupts retinal neurogenesis. Cell Res. 23, 254-273. doi: 10.1038/cr.2012.150

Chen, Y., Yang, J., Geng, H., Li, L., Li, J., Cheng, B., et al. (2019). Photoreceptor degeneration in microphthalmia (Mitf) mice: partial rescue by pigment epithelium-derived factor. Dis. Model. Mech. 12:dmm035642. doi: 10.1242/ dmm.035642

Cheng, H., Aleman, T. S., Cideciyan, A. V., Khanna, R., Jacobson, S. G., and Swaroop, A. (2006). In vivo function of the orphan nuclear receptor NR2E3 in establishing photoreceptor identity during mammalian retinal development. Hum. Mol. Genet. 15, 2588-2602. doi: 10.1093/hmg/ddl185

Chuderland, D., Ben-Ami, I., Kaplan-Kraicer, R., Grossman, H., Komsky, A., Satchi-Fainaro, R., et al. (2013). Hormonal regulation of pigment epitheliumderived factor (PEDF) in granulosa cells. Mol. Hum. Reprod. 19, 72-81. doi: 10.1093/molehr/gas046

Clevers, H., Loh, K. M., and Nusse, R. (2014). Stem cell signaling. An integral program for tissue renewal and regeneration: Wnt signaling and stem cell control. Science 346:1248012. doi: 10.1126/science.1248012

Close, J. L., Gumuscu, B., and Reh, T. A. (2005). Retinal neurons regulate proliferation of postnatal progenitors and Muller glia in the rat retina via TGF beta signaling. Development 132, 3015-3026. doi: 10.1242/dev.01882

Comitato, A., Subramanian, P., Turchiano, G., Montanari, M., Becerra, S. P., and Marigo, V. (2018). Pigment epithelium-derived factor hinders photoreceptor cell death by reducing intracellular calcium in the degenerating retina. Cell Death Dis. 9:560.

Cowan, C. S., Renner, M., Gross-Scherf, B., Goldblum, D., Munz, M., Krol, J., et al. (2019). Cell types of the human retina and its organoids at single-cell resolution: developmental convergence, transcriptomic identity, and disease map. bioRxiv [Preprint]. doi: 10.1101/703348 bioRxiv: 703348,

Crair, M. C., and Mason, C. A. (2016). Reconnecting Eye to brain. J. Neurosci. 36, 10707-10722. doi: 10.1523/jneurosci.1711-16.2016

Cruz-Martin, A., El-Danaf, R. N., Osakada, F., Sriram, B., Dhande, O. S., Nguyen, P. L., et al. (2014). A dedicated circuit links direction-selective retinal ganglion cells to the primary visual cortex. Nature 507, 358-361. doi: 10.1038/ nature 12989

Cuzzani, O. (2018). Cell therapy-based approaches to treatment of AMD. An update on current research. Retin. Phys. 15, 44-48.

Cvekl, A., and Wang, W. L. (2009). Retinoic acid signaling in mammalian eye development. Exp. Eye Res. 89, 280-291. doi: 10.1016/j.exer.2009.04.012

Dakubo, G. D., Mazerolle, C., Furimsky, M., Yu, C., St-Jacques, B., McMahon, A. P., et al. (2008). Indian hedgehog signaling from endothelial cells is required for sclera and retinal pigment epithelium development in the mouse eye. Dev. Biol. 320, 242-255. doi: 10.1016/j.ydbio.2008.05.528

Dakubo, G. D., Wang, Y. P., Mazerolle, C., Campsall, K., McMahon, A. P., and Wallace, V. A. (2003). Retinal ganglion cell-derived sonic hedgehog signaling is required for optic disc and stalk neuroepithelial cell development. Development 130, 2967-2980. doi: 10.1242/dev.00515

Das, A. V., Bhattacharya, S., Zhao, X., Hegde, G., Mallya, K., Eudy, J. D., et al. (2008). The canonical Wnt pathway regulates retinal stem cells/progenitors in concert with Notch signaling. Dev. Neurosci. 30, 389-409. doi: 10.1159/ 000178017

Dawson, D. W., Volpert, O. V., Gillis, P., Crawford, S. E., Xu, H., Benedict, W., et al. (1999). Pigment epithelium-derived factor: a potent inhibitor of angiogenesis. Science 285, 245-248. doi: 10.1126/science.285.5425.245

de Lau, W., Peng, W. C., Gros, P., and Clevers, H. (2014). The R-spondin/Lgr5/Rnf43 module: regulator of Wnt signal strength. Genes Dev. 28, 305-316. doi: 10.1101/gad.235473.113 de Lima, S., Koriyama, Y., Kurimoto, T., Oliveira, J. T., Yin, Y., Li, Y., et al. (2012). Full-length axon regeneration in the adult mouse optic nerve and partial recovery of simple visual behaviors. Proc. Natl. Acad. Sci. U.S.A. 109, 9149-9154. doi: 10.1073/pnas.1119449109

Deng, W. L., Gao, M. L., Lei, X. L., Lv, J. N., Zhao, H., He, K. W., et al. (2018). Gene correction reverses ciliopathy and photoreceptor loss in iPSC-derived retinal organoids from retinitis pigmentosa patients. Stem Cell Rep. 10, 1267-1281. doi: 10.1016/j.stemcr.2018.02.003

Dhande, O. S., and Huberman, A. D. (2014). Retinal ganglion cell maps in the brain: implications for visual processing. Curr. Opin. Neurobiol. 24, 133-142. doi: 10.1016/j.conb.2013.08.006

Di Lauro, S., Rodriguez-Crespo, D., Gayoso, M. J., Garcia-Gutierrez, M. T., Pastor, J. C., Srivastava, G. K., et al. (2016). A novel coculture model of porcine central neuroretina explants and retinal pigment epithelium cells. Mol. Vis. 22, 243-253.

Ding, X., Patel, M., and Chan, C. C. (2009). Molecular pathology of age-related macular degeneration. Prog. Retin. Eye Res. 28, 1-18.

DiStefano, T., Chen, H. Y., Panebianco, C., Kaya, K. D., Brooks, M. J., Gieser, L., et al. (2018). Accelerated and improved differentiation of retinal organoids from pluripotent stem cells in rotating-wall vessel bioreactors. Stem Cell Rep. 10, 300-313. doi: 10.1016/j.stemcr.2017.11.001

Dorgau, B., Felemban, M., Hilgen, G., Kiening, M., Zerti, D., Hunt, N. C., et al. (2019). Decellularised extracellular matrix-derived peptides from neural retina and retinal pigment epithelium enhance the expression of synaptic markers and light responsiveness of human pluripotent stem cell derived retinal organoids. Biomaterials 199, 63-75. doi: 10.1016/j.biomaterials.2019.01.028

Duester, G. (2000). Families of retinoid dehydrogenases regulating vitamin A function: production of visual pigment and retinoic acid. Eur. J. Biochem. 267, 4315-4324. doi: 10.1046/j.1432-1327.2000.01497.x

Duester, G. (2009). Keeping an eye on retinoic acid signaling during eye development. Chem. Biol. Interact. 178, 178-181. doi: 10.1016/j.cbi.2008.09.004

Ebrahimi, V., Vojoudi, E., Fazel, A., and Ebrahimzadeh-Bideskan, A. (2014). Histochemical study of retinal photoreceptors development during pre- and postnatal period and their association with retinal pigment epithelium. Iran J. Basic Med. Sci. 17, 483-489.

Erskine, L., and Herrera, E. (2014). Connecting the retina to the brain. ASN Neuro 6:1759091414562107.

Euler, T., and Wassle, H. (1995). Immunocytochemical identification of cone bipolar cells in the rat retina. J. Comp. Neurol. 361, 461-478. doi: 10.1002/cne. 903610310

Fan, J., Rohrer, B., Moiseyev, G., Ma, J.-X., and Crouch, R. K. (2003). Isorhodopsin rather than rhodopsin mediates rod function in RPE65 knock-out mice. Proc. Natl. Acad. Sci. U.S.A. 100, 13662-13667. doi: 10.1073/pnas.2234461100

Felemban, M., Dorgau, B., Hunt, N. C., Hallam, D., Zerti, D., Bauer, R., et al. (2018). Extracellular matrix component expression in human pluripotent stem cell-derived retinal organoids recapitulates retinogenesis in vivo and reveals an important role for IMPG1 and CD44 in the development of photoreceptors and interphotoreceptor matrix. Acta Biomater. 74, 207-221. doi: 10.1016/j.actbio. 2018.05.023

Finklea, K., Jansen, D. J., Johnson, J. A., Panangala, S. V., Redhead, C. S., ReyesAkinbileje, B., et al. (2015). Fetal Tissue Research: Frequently Asked Questions. Washington, DC: Congressional Research Service.

Finnemann, S. C., and Chang, Y. (2008). "Photoreceptor-RPE interactions," in Visual Transduction and Non-Visual Light Perception, eds J. Tombran-Tink and C. J. Barnstable (Totowa, NJ: Humana Press), 67-86. doi: 10.1007/978-159745-374-5_4

Fisher, S. K., and Lewis, G. P. (2006). “Chapter 115 - Cellular effects of detachment and reattachment on the neural retina and the retinal pigment epithelium," in Retina, 4th Edn, eds S. J. Ryan, D. R. Hinton, A. P. Schachat, and C. P. Wilkinson (Edinburgh: Mosby), 1991-2012. doi: 10.1016/b978-0-323-02598-0.50121-x

Fisher, S. K., and Lewis, G. P. (2010). "Chapter 71 - Retinal detachment," in Ocular Disease, eds L. A. Levin and D. M. Albert (Edinburgh: W.B. Saunders), 554-561.

Fligor, C. M., Langer, K. B., Sridhar, A., Ren, Y., Shields, P. K., Edler, M. C., et al. (2018). Three-dimensional retinal organoids facilitate the investigation of retinal ganglion cell development, organization and neurite outgrowth from human pluripotent stem cells. Sci. Rep. 8:14520. 
Fontaine, V., Kinkl, N., Sahel, J., Dreyfus, H., and Hicks, D. (1998). Survival of purified rat photoreceptors in vitro is stimulated directly by fibroblast growth factor-2. J. Neurosci. 18, 9662-9672. doi: 10.1523/jneurosci.18-23-09662.1998

Forrester, J. V., Dick, A. D., McMenamin, P. G., Roberts, F., and Pearlman, E. (2016). "Chapter 2 - Embryology and early development of the eye and adnexa," in The Eye, 4th Edn, eds J. V. Forrester, A. D. Dick, P. G. McMenamin, F. Roberts, and E. Pearlman (Philadelphia, PA: W.B. Saunders), 103-129.e8. doi: 10.1016/b978-0-7020-5554-6.00002-2

Friedman, D. S., O'Colmain, B. J., Munoz, B., Tomany, S. C., McCarty, C., de Jong, P. T., et al. (2004). Prevalence of age-related macular degeneration in the United States. Arch. Ophthalmol. 122, 564-572.

Fuhrmann, S. (2008). Wnt signaling in eye organogenesis. Organogenesis 4, 60-67. doi: $10.4161 /$ org.4.2.5850

Fuhrmann, S. (2010). Eye morphogenesis and patterning of the optic vesicle. Curr. Top. Dev. Biol. 93, 61-84. doi: 10.1016/b978-0-12-385044-7.00003-5

Fuhrmann, S., Zou, C., and Levine, E. M. (2014). Retinal pigment epithelium development, plasticity, and tissue homeostasis. Exp. Eye Res. 123, 141-150. doi: 10.1016/j.exer.2013.09.003

Fujimura, N. (2016). WNT/ $\beta$-catenin signaling in vertebrate eye development. Front. Cell Dev. Biol. 4:138. doi: 10.3389/fcell.2016.00138

Furukawa, T., Mukherjee, S., Bao, Z. Z., Morrow, E. M., and Cepko, C. L. (2000). rax, Hes1, and notch1 promote the formation of Muller glia by postnatal retinal progenitor cells. Neuron 26, 383-394. doi: 10.1016/s0896-6273(00)81171-x

Gagliardi, G., Ben M’Barek, K., Chaffiol, A., Slembrouck-Brec, A., Conart, J. B., Nanteau, C., et al. (2018). Characterization and transplantation of CD73positive photoreceptors isolated from human iPSC-derived retinal organoids. Stem Cell Rep. 11, 665-680. doi: 10.1016/j.stemcr.2018.07.005

Gamm, D. M., Clark, E., Capowski, E. E., and Singh, R. (2019). The role of FGF9 in the production of neural retina and RPE in a pluripotent stem cell model of early human retinal development. Am. J. Ophthalmol. 206, 113-131. doi: 10.1016/j.ajo.2019.04.033

Garcia, G. III, Raleigh, D. R., and Reiter, J. F. (2018). How the ciliary membrane is organized inside-out to communicate outside-in. Curr. Biol. 28, R421-R434.

Garita-Hernandez, M., Lampic, M., Chaffiol, A., Guibbal, L., Routet, F., SantosFerreira, T., et al. (2019). Restoration of visual function by transplantation of optogenetically engineered photoreceptors. Nat. Commun. 10:4524.

Gearhart, P. M., Gearhart, C., Thompson, D. A., and Petersen-Jones, S. M. (2010). Improvement of visual performance with intravitreal administration of 9-cisretinal in Rpe65-mutant dogs. Arch. Ophthalmol. 128, 1442-1448.

Gearhart, P. M., Gearhart, C. C., and Petersen-Jones, S. M. (2008). A novel method for objective vision testing in canine models of inherited retinal disease. Invest. Ophthalmol. Vis. Sci. 49, 3568-3576.

Geng, Z., Walsh, P. J., Truong, V., Hill, C., Ebeling, M., Kapphahn, R. J., et al. (2017). Generation of retinal pigmented epithelium from iPSCs derived from the conjunctiva of donors with and without age related macular degeneration. PLoS One 12:e0173575. doi: 10.1371/journal.pone.0173575

German, O. L., Buzzi, E., Rotstein, N. P., Rodriguez-Boulan, E., and Politi, L. E. (2008). Retinal pigment epithelial cells promote spatial reorganization and differentiation of retina photoreceptors. J. Neurosci. Res. 86, 3503-3514. doi: $10.1002 /$ jnr. 21813

Gerrelli, D., Lisgo, S., Copp, A. J., and Lindsay, S. (2015). Enabling research with human embryonic and fetal tissue resources. Development 142, 3073-3076. doi: $10.1242 /$ dev. 122820

Gilliam, J. C., Chang, J. T., Sandoval, I. M., Zhang, Y., Li, T., Pittler, S. J., et al. (2012). Three-dimensional architecture of the rod sensory cilium and its disruption in retinal neurodegeneration. Cell 151, 1029-1041. doi: 10.1016/j. cell.2012.10.038

Goldberg, A. F., Moritz, O. L., and Williams, D. S. (2016). Molecular basis for photoreceptor outer segment architecture. Prog. Retin. Eye Res. 55, 52-81. doi: 10.1016/j.preteyeres.2016.05.003

Gonzalez-Cordero, A., Kruczek, K., Naeem, A., Fernando, M., Kloc, M., Ribeiro, J., et al. (2017). Recapitulation of human retinal development from human pluripotent stem cells generates transplantable populations of cone photoreceptors. Stem Cell Rep. 9, 820-837. doi: 10.1016/j.stemcr.2017.07.022

Gopalakrishnan, J. (2019). The emergence of stem cell-based brain organoids: trends and challenges. Bioessays 41:e1900011.

Grebenyuk, S., and Ranga, A. (2019). Engineering organoid vascularization. Front. Bioeng. Biotechnol. 7:39. doi: 10.3389/fbioe.2019.00039
Greenlee, H., Hecker, 1, Akimoto, M., and Swaroop, A. (2006). Expression of the Igf- 1 receptor in developing photoreceptors of the mouse retina and the importance of Igf-1 signaling during photoreceptor differentiation. Invest. Ophthalmol. Vis. Sci. 47:4190.

Gregerson, D. S., Lew, K. L., McPherson, S. W., Heuss, N. D., and Ferrington, D. A. (2006). RPE cells resist bystander killing by CTLs, but are highly susceptible to antigen-dependent CTL killing. Invest. Ophthalmol. Vis. Sci. 47, 5385-5394.

Gu, Q., Tomaskovic-Crook, E., Wallace, G. G., and Crook, J. M. (2018). Engineering human neural tissue by 3D bioprinting. Methods Mol. Biol. 1758, 129-138. doi: 10.1007/978-1-4939-7741-3_10

Guo, Y., Wang, P., Ma, J. H., Cui, Z., Yu, Q., Liu, S., et al. (2019). Modeling retinitis pigmentosa: retinal organoids generated from the iPSCs of a patient with the USH2A mutation show early developmental abnormalities. Front. Cell. Neurosci. 13:361. doi: 10.3389/fncel.2019.00361

Ha, T., Moon, K. H., Dai, L., Hatakeyama, J., Yoon, K., Park, H. S., et al. (2017). The retinal pigment epithelium is a notch signaling niche in the mouse retina. Cell Rep. 19, 351-363. doi: 10.1016/j.celrep.2017.03.040

Haderspeck, J. C., Chuchuy, J., Kustermann, S., Liebau, S., and Loskill, P. (2019). Organ-on-a-chip technologies that can transform ophthalmic drug discovery and disease modeling. Expert Opin. Drug Discov. 14, 47-57. doi: 10.1080/ 17460441.2019.1551873

Hallam, D., Hilgen, G., Dorgau, B., Zhu, L., Yu, M., Bojic, S., et al. (2018). Humaninduced pluripotent stem cells generate light responsive retinal organoids with variable and nutrient-dependent efficiency. Stem Cells 36, 1535-1551. doi: 10.1002/stem. 2883

Hambright, D., Park, K. Y., Brooks, M., McKay, R., Swaroop, A., and Nasonkin, I. O. (2012). Long-term survival and differentiation of retinal neurons derived from human embryonic stem cell lines in un-immunosuppressed mouse retina. Mol. Vis. 18, 920-936.

Hamel, C. P. (2007). Cone rod dystrophies. Orphanet J. Rare Dis. 2:7.

Hasegawa, T., McLeod, D. S., Prow, T., Merges, C., Grebe, R., and Lutty, G. A. (2008). Vascular precursors in developing human retina. Invest. Ophthalmol. Vis. Sci. 49, 2178-2192.

Heavner, W., and Pevny, L. (2012). Eye development and retinogenesis. Cold Spring Harb. Perspect. Biol. 4:a008391. doi: 10.1101/cshperspect.a008391

Heber-Katz, E. (2017). Oxygen, metabolism, and regeneration: lessons from mice. Trends Mol. Med. 23, 1024-1036. doi: 10.1016/j.molmed.2017.08.008

Hendrickson, A. (2016). Development of retinal layers in prenatal human retina. Am. J. Ophthalmol. 161, 29-35.e1. doi: 10.1016/j.ajo.2015.09.023

Hendrickson, A., Bumsted-O'Brien, K., Natoli, R., Ramamurthy, V., Possin, D., and Provis, J. (2008). Rod photoreceptor differentiation in fetal and infant human retina. Exp. Eye Res. 87, 415-426. doi: 10.1016/j.exer.2008.07.016

Hendrickson, A., Djajadi, H., Erickson, A., and Possin, D. (2006). Development of the human retina in the absence of ganglion cells. Exp. Eye Res. 83, 920-931. doi: 10.1016/j.exer.2006.04.017

Ho, T. C., Chen, S. L., Shih, S. C., Chang, S. J., Yang, S. L., Hsieh, J. W., et al. (2011). Pigment epithelium-derived factor (PEDF) promotes tumor cell death by inducing macrophage membrane tumor necrosis factor-related apoptosisinducing ligand (TRAIL). J. Biol. Chem. 286, 35943-35954. doi: 10.1074/jbc. $\mathrm{m} 111.266064$

Hochmann, S., Kaslin, J., Hans, S., Weber, A., Machate, A., Geffarth, M., et al. (2012). Fgf signaling is required for photoreceptor maintenance in the adult zebrafish retina. PLoS One 7:e30365. doi: 10.1371/journal.pone.0030365

Holmes, D. (2018a). Reconstructing the retina. Nature 561, S2-S3.

Holmes, D. (2018b). Retinal repair: visions of the future. Nature 561:S1.

Horsford, D. J., Nguyen, M. T., Sellar, G. C., Kothary, R., Arnheiter, H., and McInnes, R. R. (2005). Chx10 repression of Mitf is required for the maintenance of mammalian neuroretinal identity. Development 132, 177-187. doi: 10.1242/ dev.01571

Hoshino, A., Ratnapriya, R., Brooks, M. J., Chaitankar, V., Wilken, M. S., Zhang, C., et al. (2017). Molecular anatomy of the developing human retina. Dev. Cell 43, 763-779.e4.

Hsu, Y. T., and Molday, R. S. (1993). Modulation of the cGMP-gated channel of rod photoreceptor cells by calmodulin. Nature 361, 76-79. doi: 10.1038/361076a0

Huang, K. C., Wang, M. L., Chen, S. J., Kuo, J. C., Wang, W. J., Nhi Nguyen, P. N., et al. (2019). Morphological and molecular defects in human three-dimensional retinal organoid model of X-linked juvenile retinoschisis. Stem Cell Rep. 13, 906-923. doi: 10.1016/j.stemcr.2019.09.010 
Huang, W., Fileta, J., Guo, Y., and Grosskreutz, C. L. (2006). Downregulation of Thy1 in retinal ganglion cells in experimental glaucoma. Curr. Eye Res. 31, 265-271. doi: 10.1080/02713680500545671

Hughes, J. M., Groot, A. J., van der Groep, P., Sersansie, R., Vooijs, M., van Diest, P. J., et al. (2010). Active HIF-1 in the normal human retina. J. Histochem. Cytochem. 58, 247-254. doi: 10.1369/jhc.2009.953786

Hughes, S., Yang, H., and Chan-Ling, T. (2000). Vascularization of the human fetal retina: roles of vasculogenesis and angiogenesis. Invest. Ophthalmol. Vis. Sci. 41, 1217-1228.

Hunt, D. M., and Peichl, L. (2014). S cones: evolution, retinal distribution, development, and spectral sensitivity. Vis. Neurosci. 31, 115-138. doi: 10.1017/ s0952523813000242

Idelson, M., Alper, R., Obolensky, A., Ben-Shushan, E., Hemo, I., YachimovichCohen, N., et al. (2009). Directed differentiation of human embryonic stem cells into functional retinal pigment epithelium cells. Cell Stem Cell 5, 396-408.

Idelson, M., Alper, R., Obolensky, A., Yachimovich-Cohen, N., Rachmilewitz, J., Ejzenberg, A., et al. (2018). Immunological properties of human embryonic stem cell-derived retinal pigment epithelial cells. Stem Cell Rep. 11, 681-695. doi: 10.1016/j.stemcr.2018.07.009

Ishikawa, M., Sawada, Y., and Yoshitomi, T. (2015). Structure and function of the interphotoreceptor matrix surrounding retinal photoreceptor cells. Exp. Eye Res. 133, 3-18. doi: 10.1016/j.exer.2015.02.017

Jablonski, M. M., Tombran-Tink, J., Mrazek, D. A., and Iannaccone, A. (2000). Pigment epithelium-derived factor supports normal development of photoreceptor neurons and opsin expression after retinal pigment epithelium removal. J. Neurosci. 20, 7149-7157. doi: 10.1523/jneurosci.20-19-07149.2000

Jha, B. S., and Bharti, K. (2015). Regenerating retinal pigment epithelial cells to cure blindness: a road towards personalized artificial tissue. Curr. Stem Cell Rep. 1, 79-91. doi: 10.1007/s40778-015-0014-4

Jiang, N., Zou, C., Zhu, Y., Luo, Y., Chen, L., Lei, Y., et al. (2020). HIF-1\&-regulated miR-1275 maintains stem cell-like phenotypes and promotes the progression of LUAD by simultaneously activating Wnt/\&\#946;-catenin and Notch signaling. Theranostics 10, 2553-2570.

Jin, M., Li, S., Nusinowitz, S., Lloyd, M., Hu, J., Radu, R. A., et al. (2009). The role of interphotoreceptor retinoid-binding protein on the translocation of visual retinoids and function of cone photoreceptors. J. Neurosci. 29, 1486-1495. doi: 10.1523/jneurosci.3882-08.2009

Jin, Z. B., Okamoto, S., Osakada, F., Homma, K., Assawachananont, J., Hirami, Y., et al. (2011). Modeling retinal degeneration using patient-specific induced pluripotent stem cells. PLoS One 6:e17084. doi: 10.1371/journal.pone.001 7084

Jin, Z. B., Okamoto, S., Xiang, P., and Takahashi, M. (2012). Integration-free induced pluripotent stem cells derived from retinitis pigmentosa patient for disease modeling. Stem Cells Transl. Med. 1, 503-509. doi: 10.5966/sctm.20120005

Johnson, E. C., Guo, Y., Cepurna, W. O., and Morrison, J. C. (2009). Neurotrophin roles in retinal ganglion cell survival: lessons from rat glaucoma models. Exp. Eye Res. 88, 808-815. doi: 10.1016/j.exer.2009.02.004

Jukic, A. M., Baird, D. D., Weinberg, C. R., McConnaughey, D. R., and Wilcox, A. J. (2013). Length of human pregnancy and contributors to its natural variation. Hum. Reproduc. 28, 2848-2855. doi: 10.1093/humrep/det297

Kanemura, H., Go, M. J., Nishishita, N., Sakai, N., Kamao, H., Sato, Y., et al. (2013). Pigment epithelium-derived factor secreted from retinal pigment epithelium facilitates apoptotic cell death of iPSC. Sci. Rep. 3:2334.

Kaplan, H. J., Wang, W., and Dean, D. C. (2017). Restoration of cone photoreceptor function in retinitis pigmentosa. Transl. Vis. Sci. Technol. 6:5. doi: 10.1167/tvst. 6.5 .5

Kashani, A. H., Lebkowski, J. S., Rahhal, F. M., Avery, R. L., Salehi-Had, H., Dang, W., et al. (2018). A bioengineered retinal pigment epithelial monolayer for advanced, dry age-related macular degeneration. Sci. Transl. Med. 10:eaao4097.

Kefalov, V. J. (2012). Rod and cone visual pigments and phototransduction through pharmacological, genetic, and physiological approaches. J. Biol. Chem. 287, 1635-1641. doi: 10.1074/jbc.r111.303008

Kelley, R. A., Al-Ubaidi, M. R., and Naash, M. I. (2015). Retbindin is an extracellular riboflavin-binding protein found at the photoreceptor/retinal pigment epithelium interface. J. Biol. Chem. 290, 5041-5052. doi: 10.1074/jbc. m114.624189
Kessler, M., Hoffmann, K., Brinkmann, V., Thieck, O., Jackisch, S., Toelle, B., et al. (2015). The Notch and Wnt pathways regulate stemness and differentiation in human fallopian tube organoids. Nat. Commun. 6:8989.

Kevany, B. M., and Palczewski, K. (2010). Phagocytosis of retinal rod and cone photoreceptors. Physiology (Bethesda) 25, 8-15. doi: 10.1152/physiol.00038. 2009

Khanna, H., Akimoto, M., Siffroi-Fernandez, S., Friedman, J. S., Hicks, D., and Swaroop, A. (2006). Retinoic acid regulates the expression of photoreceptor transcription factor NRL. J. Biol. Chem. 281, 27327-27334. doi: 10.1074/jbc. m605500200

Kinnebrew, M., Iverson, E. J., Patel, B. B., Pusapati, G. V., Kong, J. H., Johnson, K. A., et al. (2019). Cholesterol accessibility at the ciliary membrane controls hedgehog signaling. Elife 8:50051.

Kiser, P. D., Golczak, M., and Palczewski, K. (2014). Chemistry of the retinoid (visual) cycle. Chem. Rev. 114, 194-232. doi: 10.1021/cr400107q

Klein, R., Klein, B. E., and Linton, K. L. (1992). Prevalence of age-related maculopathy. The Beaver Dam Eye Study. Ophthalmology 99, 933-943.

Klein, R., Wang, Q., Klein, B. E., Moss, S. E., and Meuer, S. M. (1995). The relationship of age-related maculopathy, cataract, and glaucoma to visual acuity. Invest. Ophthalmol. Vis. Sci. 36, 182-191.

Kobayashi, M., Tokuda, K., Kobayashi, Y., Yamashiro, C., Uchi, S. H., Hatano, M., et al. (2019). Suppression of epithelial-mesenchymal transition in retinal pigment epithelial cells by an MRTF-a inhibitor. Invest. Ophthalmol. Vis. Sci. $60,528-537$.

Kolb, H. (1995). "Photoreceptors," in Webvision: The Organization of the Retina and Visual System, eds H. Kolb, E. Fernandez, and R. Nelson (Salt Lake City, UT: University of Utah Health Sciences Center).

Kolb, H. (2005). "Facts and figures concerning the human retina," in Webvision: The Organization of the Retina and Visual System, eds H. Kolb, E. Fernandez, and R. Nelson (Salt Lake City, UT: University of Utah Health Sciences Center).

Kong, J. H., Siebold, C., and Rohatgi, R. (2019). Biochemical mechanisms of vertebrate hedgehog signaling. Development 146:dev166892. doi: 10.1242/dev. 166892

Kostic, C., and Arsenijevic, Y. (2016). Animal modelling for inherited central vision loss. J. Pathol. 238, 300-310. doi: 10.1002/path.4641

Kroeger, H., LaVail, M. M., and Lin, J. H. (2014). "Endoplasmic reticulum stress in vertebrate mutant rhodopsin models of retinal degeneration," in Retinal Degenerative Diseases, eds J. D. Ash, C. Grimm, J. G. Hollyfield, R. E. Anderson, M. M. LaVail, and C. Bowes Rickman (New York, NY: Springer New York), 585-592. doi: 10.1007/978-1-4614-3209-8_74

Kurimoto, T., Yin, Y., Omura, K., Gilbert, H. Y., Kim, D., Cen, L. P., et al. (2010). Long-distance axon regeneration in the mature optic nerve: contributions of oncomodulin, cAMP, and pten gene deletion. J. Neurosci. 30, 15654-15663. doi: 10.1523/jneurosci.4340-10.2010

Kuwahara, A., Ozone, C., Nakano, T., Saito, K., Eiraku, M., and Sasai, Y. (2015). Generation of a ciliary margin-like stem cell niche from self-organizing human retinal tissue. Nat. Commun. 6:6286.

Kuwahara, A., Yamasaki, S., Mandai, M., Watari, K., Matsushita, K., Fujiwara, M., et al. (2019). Preconditioning the initial state of feeder-free human pluripotent stem cells promotes self-formation of three-dimensional retinal tissue. Sci. Rep. 9:18936.

Laha, B., Stafford, B. K., and Huberman, A. D. (2017). Regenerating optic pathways from the eye to the brain. Science 356, 1031-1034. doi: 10.1126/science.aal 5060

Lakowski, J., Welby, E., Budinger, D., Di Marco, F., Di Foggia, V., Bainbridge, J. W. B., et al. (2018). Isolation of human photoreceptor precursors via a cell surface marker panel from stem cell-derived retinal organoids and fetal retinae. Stem Cells 36, 709-722. doi: 10.1002/stem.2775

Lamba, D. A., Karl, M. O., Ware, C. B., and Reh, T. A. (2006). Efficient generation of retinal progenitor cells from human embryonic stem cells. Proc. Natl. Acad. Sci. U.S.A. 103, 12769-12774.

Lamba, D. A., McUsic, A., Hirata, R. K., Wang, P. R., Russell, D., and Reh, T. A. (2010). Generation, purification and transplantation of photoreceptors derived from human induced pluripotent stem cells. PLoS One 5:e8763. doi: 10.1371/ journal.pone.0008763

Lancaster, M. A., and Huch, M. (2019). Disease modelling in human organoids. Dis. Model. Mech. 12:dmm039347. doi: 10.1242/dmm.039347 
Lane, A., Jovanovic, K., Shortall, C., Ottaviani, D., Panes, A. B., Palfi, A., et al. (2020). Modelling and rescue of RP2 retinitis pigmentosa using iPSC derived retinal organoids. bioRxiv [Preprint]. doi: 10.1101/2020.01.28.923227

Lee, J. W., Ko, J., Ju, C., and Eltzschig, H. K. (2019). Hypoxia signaling in human diseases and therapeutic targets. Exp. Mol. Med. 51:68.

Levine, E. M., Roelink, H., Turner, J., and Reh, T. A. (1997). Sonic hedgehog promotes rod photoreceptor differentiation in mammalian retinal cells in vitro. J. Neurosci. 17, 6277-6288. doi: 10.1523/jneurosci.17-16-06277.1997

Li, J., Wang, S., Anderson, C., Zhao, F., Qin, Y., Wu, D., et al. (2016). Requirement of Smad4 from ocular surface ectoderm for retinal development. PLoS One 11:e0159639. doi: 10.1371/journal.pone.0159639

Li, L., Rao, K. N., Zheng-Le, Y., Hurd, T. W., Lillo, C., and Khanna, H. (2015). Loss of retinitis pigmentosa $2(\mathrm{RP} 2)$ protein affects cone photoreceptor sensory cilium elongation in mice. Cytoskeleton (Hoboken) 72, 447-454. doi: 10.1002/ cm. 21255

Li, P., Kleinstiver, B. P., Leon, M. Y., Prew, M. S., Navarro-Gomez, D., Greenwald, S. H., et al. (2018). Allele-specific CRISPR/Cas9 genome editing of the singlebase $\mathrm{P} 23 \mathrm{H}$ mutation for rhodopsin associated dominant retinitis pigmentosa. bioRxiv [Preprint]. doi: 10.1101/197962

Lin, B., McLelland, B. T., Mathur, A., Aramant, R. B., and Seiler, M. J. (2018). Sheets of human retinal progenitor transplants improve vision in rats with severe retinal degeneration. Exp. Eye Res. 174, 13-28. doi: 10.1016/j.exer.2018.05.017

Lin, B., and Peng, E. B. (2013). Retinal ganglion cells are resistant to photoreceptor loss in retinal degeneration. PLoS One 8:e68084. doi: 10.1371/journal.pone. 0068084

Littink, K. W., Stappers, P. T. Y., Riemslag, F. C. C., Talsma, H. E., van Genderen, M. M., Cremers, F. P. M., et al. (2018). Autosomal recessive NRL mutations in patients with enhanced S-Cone syndrome. Genes (Basel) 9:68. doi: 10.3390/ genes 9020068

Liu, H., Thurig, S., Mohamed, O., Dufort, D., and Wallace, V. A. (2006). Mapping canonical Wnt signaling in the developing and adult retina. Invest. Ophthalmol. Vis. Sci. 47, 5088-5097.

Liu, W., Jin, G., Long, C., Zhou, X., Tang, Y., Huang, S., et al. (2013). Blockage of notch signaling inhibits the migration and proliferation of retinal pigment epithelial cells. ScientificWorldJournal 2013:178708.

Liu, W., Lagutin, O., Swindell, E., Jamrich, M., and Oliver, G. (2010). Neuroretina specification in mouse embryos requires Six3-mediated suppression of Wnt8b in the anterior neural plate. J. Clin. Invest. 120, 3568-3577. doi: 10.1172/ jci43219

Liu, X., Bulgakov, O. V., Darrow, K. N., Pawlyk, B., Adamian, M., Liberman, M. C., et al. (2007). Usherin is required for maintenance of retinal photoreceptors and normal development of cochlear hair cells. Proc. Natl. Acad. Sci. U.S.A. 104, 4413-4418. doi: 10.1073/pnas.0610950104

Livesey, F. J., and Cepko, C. L. (2001). Vertebrate neural cell-fate determination: lessons from the retina. Nat. Rev. Neurosci. 2, 109-118. doi: 10.1038/35053522

Locker, M., Agathocleous, M., Amato, M. A., Parain, K., Harris, W. A., and Perron, M. (2006). Hedgehog signaling and the retina: insights into the mechanisms controlling the proliferative properties of neural precursors. Genes Dev. 20, 3036-3048. doi: 10.1101/gad.391106

Lodato, S., and Arlotta, P. (2015). Generating neuronal diversity in the mammalian cerebral cortex. Annu. Rev. Cell Dev. Biol. 31, 699-720. doi: 10.1146/annurevcellbio-100814-125353

Lofqvist, C., Willett, K. L., Aspegren, O., Smith, A. C., Aderman, C. M., Connor, K. M., et al. (2009). Quantification and localization of the IGF/insulin system expression in retinal blood vessels and neurons during oxygen-induced retinopathy in mice. Invest. Ophthalmol. Vis. Sci. 50, 1831-1837.

Lolley, R. N., Rong, H., and Craft, C. M. (1994). Linkage of photoreceptor degeneration by apoptosis with inherited defect in phototransduction. Invest. Ophthalmol. Vis. Sci. 35, 358-362.

Longbottom, R., Fruttiger, M., Douglas, R. H., Martinez-Barbera, J. P., Greenwood, J., and Moss, S. E. (2009). Genetic ablation of retinal pigment epithelial cells reveals the adaptive response of the epithelium and impact on photoreceptors. Proc. Natl. Acad. Sci. U.S.A. 106, 18728-18733. doi: 10.1073/pnas.090259 3106

Lu, A. Q., Popova, E. Y., and Barnstable, C. J. (2017). Activin signals through SMAD2/3 to increase photoreceptor precursor yield during embryonic stem cell differentiation. Stem Cell Rep. 9, 838-852. doi: 10.1016/j.stemcr.2017. 06.021
Luo, D.-G., Xue, T., and Yau, K. W (2008). How vision begins: an odyssey. Proc. Natl. Acad. Sci. U.S.A. 105, 9855-9862. doi: 10.1073/pnas.070840 5105

Luo, Z., Zhong, X., Li, K., Xie, B., Liu, Y., Ye, M., et al. (2018). An optimized system for effective derivation of three-dimensional retinal tissue via Wnt signaling regulation. Stem Cells 36, 1709-1722. doi: 10.1002/stem.2890

Lutty, G., Ikeda, K., Chandler, C., and McLeod, D. S. (1991). Immunohistochemical localization of transforming growth factor-beta in human photoreceptors. Curr. Eye. Res. 10, 61-74. doi: 10.3109/02713689109007611

Lutty, G. A., Merges, C., Threlkeld, A. B., Crone, S., and McLeod, D. S. (1993). Heterogeneity in localization of isoforms of TGF-beta in human retina, vitreous, and choroid. Invest. Ophthalmol. Vis. Sci. 34, 477-487.

Ma, W., Silverman, S. M., Zhao, L., Villasmil, R., Campos, M. M., Amaral, J., et al. (2019). Absence of TGFbeta signaling in retinal microglia induces retinal degeneration and exacerbates choroidal neovascularization. Elife 8:e42049.

Mack, A. F., and Fernald, R. D. (1993). Regulation of cell division and rod differentiation in the teleost retina. Brain Res. Dev. Brain Res. 76, 183-187. doi: 10.1016/0165-3806(93)90206-p

Makin, S. (2019). Four technologies that could transform the treatment of blindness. Nature 568:S1.

Malchiodi-Albedi, F., Feher, J., Caiazza, S., Formisano, G., Perilli, R., Falchi, M., et al. (1998). PEDF (pigment epithelium-derived factor) promotes increase and maturation of pigment granules in pigment epithelial cells in neonatal albino rat retinal cultures. Int. J. Dev. Neurosci. 16, 423-432. doi: 10.1016/s0736-5748(98) 00014-8

Mandai, M., Fujii, M., Hashiguchi, T., Sunagawa, G. A., Ito, S. I., Sun, J., et al. (2017a). iPSC-derived retina transplants improve vision in rd1 End-stage retinal-degeneration mice. Stem Cell Rep. 8:489. doi: 10.1016/j.stemcr.2017. 01.018

Mandai, M., Watanabe, A., Kurimoto, Y., Hirami, Y., Morinaga, C., Daimon, T., et al. (2017b). Autologous induced stem-cell-derived retinal cells for macular degeneration. N. Engl. J. Med. 376, 1038-1046.

Manuel, M., Pratt, T., Liu, M., Jeffery, G., and Price, D. J. (2008). Overexpression of Pax6 results in microphthalmia, retinal dysplasia and defective retinal ganglion cell axon guidance. BMC Dev. Biol. 8:59. doi: 10.1186/1471-213X-8-59

Marmor, M. F. (2013). “Chapter 19 - mechanisms of normal retinal adhesion," in Retina, 5th Edn, eds S. R. Sadda, D. R. Hinton, A. P. Schachat, S. R. Sadda, C. P. Wilkinson, P. Wiedemann, et al. (London: W.B. Saunders), 447-464. doi: 10.1016/b978-1-4557-0737-9.00019-9

Marquardt, T., and Gruss, P. (2002). Generating neuronal diversity in the retina: one for nearly all. Trends Neurosci. 25, 32-38. doi: 10.1016/s0166-2236(00) 02028-2

Maruotti, J., Sripathi, S. R., Bharti, K., Fuller, J., Wahlin, K. J., Ranganathan, V., et al. (2015). Small-molecule-directed, efficient generation of retinal pigment epithelium from human pluripotent stem cells. Proc. Natl. Acad. Sci. U.S.A. 112, 10950-10955. doi: 10.1073/pnas.1422818112

Masaeli, E., Forster, V., Picaud, S., Karamali, F., Nasr-Esfahani, M. H., and Marquette, C. (2020). Tissue engineering of retina through high resolution 3dimensional inkjet bioprinting. Biofabrication 12:025006. doi: 10.1088/17585090/ab4a20

Mathieson, K., Loudin, J., Goetz, G., Huie, P., Wang, L., Kamins, T. I., et al. (2012). Photovoltaic retinal prosthesis with high pixel density. Nat. Photonics 6, 391-397. doi: 10.1038/nphoton.2012.104

Matsushima, D., Heavner, W., and Pevny, L. H. (2011). Combinatorial regulation of optic cup progenitor cell fate by SOX2 and PAX6. Development 138, 443-454. doi: 10.1242/dev.055178

Matt, N., Dupe, V., Garnier, J. M., Dennefeld, C., Chambon, P., Mark, M., et al. (2005). Retinoic acid-dependent eye morphogenesis is orchestrated by neural crest cells. Development 132, 4789-4800. doi: 10.1242/dev.02031

May-Simera, H. L., Wan, Q., Jha, B. S., Hartford, J., Khristov, V., Dejene, R., et al. (2018). Primary cilium-mediated retinal pigment epithelium maturation is disrupted in ciliopathy patient cells. Cell Rep. 22, 189-205. doi: 10.1016/j. celrep.2017.12.038

Mazzoni, F., Safa, H., and Finnemann, S. C. (2014). Understanding photoreceptor outer segment phagocytosis: use and utility of RPE cells in culture. Exp. Eye Res. 126, 51-60. doi: 10.1016/j.exer.2014.01.010

McGill, T. J., Bohana-Kashtan, O., Stoddard, J. W., Andrews, M. D., Pandit, N., Rosenberg-Belmaker, L. R., et al. (2017). Long-term efficacy of GMP grade 
Xeno-Free hESC-derived RPE cells following transplantation. Transl. Vis. Sci. Technol. 6:17. doi: 10.1167/tvst.6.3.17

McLelland, B. T., Lin, B., Mathur, A., Aramant, R. B., Thomas, B. B., Nistor, G., et al. (2018). Transplanted hESC-derived retina organoid sheets differentiate, integrate, and improve visual function in retinal degenerate rats. Invest. Ophthalmol. Vis. Sci. 59, 2586-2603.

McLeod, D. S., Hasegawa, T., Prow, T., Merges, C., and Lutty, G. (2006). The initial fetal human retinal vasculature develops by vasculogenesis. Dev. Dyn. 235, 3336-3347. doi: 10.1002/dvdy.20988

McUsic, A. C., Lamba, D. A., and Reh, T. A. (2012). Guiding the morphogenesis of dissociated newborn mouse retinal cells and hES cell-derived retinal cells by soft lithography-patterned microchannel PLGA scaffolds. Biomaterials 33, 1396-1405. doi: 10.1016/j.biomaterials.2011.10.083

Meadows, K. L., and Hurwitz, H. I. (2012). Anti-VEGF therapies in the clinic. Cold Spring Harb. Perspect. Med. 2:a006577. doi: 10.1101/cshperspect.a006577

Mears, A. J., Hiriyanna, S., Vervoort, R., Yashar, B., Gieser, L., Fahrner, S., et al. (2000). Remapping of the RP15 locus for X-linked cone-rod degeneration to Xp11.4-p21.1, and identification of a de novo insertion in the RPGR exon ORF15. Am. J. Hum. Genet. 67, 1000-1003. doi: 10.1086/303091

Mears, A. J., Kondo, M., Swain, P. K., Takada, Y., Bush, R. A., Saunders, T. L., et al. (2001). Nrl is required for rod photoreceptor development. Nat. Genet. 29, 447-452. doi: 10.1038/ng774

Megaw, R., Abu-Arafeh, H., Jungnickel, M., Mellough, C., Gurniak, C., Witke, W., et al. (2017). Gelsolin dysfunction causes photoreceptor loss in induced pluripotent cell and animal retinitis pigmentosa models. Nat. Commun. 8:271.

Mellough, C. B., Collin, J., Khazim, M., White, K., Sernagor, E., Steel, D. H., et al. (2015). IGF-1 signaling plays an important role in the formation of threedimensional laminated neural retina and other ocular structures from human embryonic stem cells. Stem Cells 33, 2416-2430. doi: 10.1002/stem.2023

Mellough, C. B., Collin, J., Queen, R., Hilgen, G., Dorgau, B., Zerti, D., et al. (2019). Systematic comparison of retinal organoid differentiation from human pluripotent stem cells reveals stage specific, cell line, and methodological differences. Stem Cells Transl. Med. 8, 694-706.

Meyer, J. S., Shearer, R. L., Capowski, E. E., Wright, L. S., Wallace, K. A., McMillan, E. L., et al. (2009). Modeling early retinal development with human embryonic and induced pluripotent stem cells. Proc. Natl. Acad. Sci. U.S.A. 106, 1669816703.

Mic, F. A., Molotkov, A., Molotkova, N., and Duester, G. (2004). Raldh2 expression in optic vesicle generates a retinoic acid signal needed for invagination of retina during optic cup formation. Dev. Dyn. 231, 270-277. doi: 10.1002/dvdy.20128

Milam, A. H., Dacey, D. M., and Dizhoor, A. M. (1993). Recoverin immunoreactivity in mammalian cone bipolar cells. Vis. Neurosci. 10, 1-12. doi: $10.1017 /$ s0952523800003175

Mills, E. A., and Goldman, D. (2017). The regulation of notch signaling in retinal development and regeneration. Curr. Pathobiol. Rep. 5, 323-331. doi: 10.1007/ s40139-017-0153-7

Mo, X., Yokoyama, A., Oshitari, T., Negishi, H., Dezawa, M., Mizota, A., et al. (2002). Rescue of axotomized retinal ganglion cells by BDNF gene electroporation in adult rats. Invest. Ophthalmol. Vis. Sci. 43, 2401-2405.

Molday, R. S. (1998). Photoreceptor membrane proteins, phototransduction, and retinal degenerative diseases. The Friedenwald Lecture. Invest. Ophthalmol. Vis. Sci. 39, 2491-2513.

Molday, R. S., and Moritz, O. L. (2015). Photoreceptors at a glance. J. Cell Sci. 128, 4039-4045. doi: 10.1242/jcs. 175687

Molyneaux, B. J., Arlotta, P., Menezes, J. R. L., and Macklis, J. D. (2007). Neuronal subtype specification in the cerebral cortex. Nat. Rev. Neurosci. 8, 427-437. doi: $10.1038 / \mathrm{nrn} 2151$

Moore, K. B., Mood, K., Daar, I. O., and Moody, S. A. (2004). Morphogenetic movements underlying eye field formation require interactions between the FGF and ephrinB1 signaling pathways. Dev. Cell 6, 55-67. doi: 10.1016/s15345807(03)00395-2

Mowat, F. M., Petersen-Jones, S. M., Williamson, H., Williams, D. L., Luthert, P. J., Ali, R. R., et al. (2008). Topographical characterization of cone photoreceptors and the area centralis of the canine retina. Mol. Vis. 14, 2518-2527.

Murali, D., Yoshikawa, S., Corrigan, R. R., Plas, D. J., Crair, M. C., Oliver, G., et al. (2005). Distinct developmental programs require different levels of Bmp signaling during mouse retinal development. Development 132, 913-923. doi: $10.1242 /$ dev. 01673
Myers, B. R., Sever, N., Chong, Y. C., Kim, J., Belani, J. D., Rychnovsky, S., et al. (2013). Hedgehog pathway modulation by multiple lipid binding sites on the smoothened effector of signal response. Dev. Cell 26, 346-357. doi: 10.1016/j. devcel.2013.07.015

Nakano, T., Ando, S., Takata, N., Kawada, M., Muguruma, K., Sekiguchi, K., et al. (2012). Self-formation of optic cups and storable stratified neural retina from human ESCs. Cell Stem Cell 10, 771-785. doi: 10.1016/j.stem.2012.05.009

Nakayama, A., Nguyen, M. T., Chen, C. C., Opdecamp, K., Hodgkinson, C. A., and Arnheiter, H. (1998). Mutations in microphthalmia, the mouse homolog of the human deafness gene MITF, affect neuroepithelial and neural crest-derived melanocytes differently. Mech. Dev. 70, 155-166. doi: 10.1016/s0925-4773(97) 00188-3

Nakazawa, T., Tamai, M., and Mori, N. (2002). Brain-derived neurotrophic factor prevents axotomized retinal ganglion cell death through MAPK and PI3K signaling pathways. Invest. Ophthalmol. Vis. Sci. 43, 3319-3326.

Nasonkin, I. O., Bin, L., Binette, F., Hogge, G., Aramant, R., Singh, R. K., et al. (2019). Transplantation of human embryonic stem cell derived retinal tissue in the subretinal space of immunodeficient rats with retinal degeneration (RD). ARVO meeting abstract. Invest. Ophthalmol. Vis. Sci. 60:3109.

Nasonkin, I. O., Merbs, S. L., Lazo, K., Oliver, V. F., Brooks, M., Patel, K., et al. (2013). Conditional knockdown of DNA methyltransferase 1 reveals a key role of retinal pigment epithelium integrity in photoreceptor outer segment morphogenesis. Development 140, 1330-1341. doi: 10.1242/dev.086603

Nauta, T. D., van Hinsbergh, V. W., and Koolwijk, P. (2014). Hypoxic signaling during tissue repair and regenerative medicine. Int. J. Mol. Sci. 15, 19791-19815. doi: 10.3390/ijms151119791

NCSL (2008). Embryonic and Fetal Research Laws. Washington, DC: National Conference of State Legislatures.

Nelius, T., Samathanam, C., Martinez-Marin, D., Gaines, N., Stevens, J., Hickson, J., et al. (2013). Positive correlation between PEDF expression levels and macrophage density in the human prostate. Prostate 73, 549-561. doi: 10.1002/ pros. 22595

Neumann, C. J., and Nuesslein-Volhard, C. (2000). Patterning of the zebrafish retina by a wave of sonic hedgehog activity. Science 289, 2137-2139. doi: 10.1126/science.289.5487.2137

Ng, L., Hurley, J. B., Dierks, B., Srinivas, M., Salto, C., Vennstrom, B., et al. (2001). A thyroid hormone receptor that is required for the development of green cone photoreceptors. Nat. Genet. 27, 94-98. doi: 10.1038/83829

Ng, L., Lu, A., Swaroop, A., Sharlin, D. S., Swaroop, A., and Forrest, D. (2011). Two transcription factors can direct three photoreceptor outcomes from rod precursor cells in mouse retinal development. J. Neurosci. 31, 11118-11125. doi: 10.1523/jneurosci.1709-11.2011

Ng, S. K., Wood, J. P., Chidlow, G., Han, G., Kittipassorn, T., Peet, D. J., et al. (2015). Cancer-like metabolism of the mammalian retina. Clin. Exp. Ophthalmol. 43, 367-376. doi: 10.1111/ceo.12462

Nguyen, M., and Arnheiter, H. (2000). Signaling and transcriptional regulation in early mammalian eye development: a link between FGF and MITF. Development 127, 3581-3591.

NIH (2009). FAQs on the Policy and Procedures for Research Using Human Fetal Tissue in the IRP. Bethesda, MD: National Institutes of Health.

O'Brien, K. M. B., Cheng, H., Jiang, Y., Schulte, D., Swaroop, A., and Hendrickson, A. E. (2004). Expression of photoreceptor-specific nuclear receptor NR2E3 in rod photoreceptors of fetal human retina. Invest. Ophthalmol. Vis. Sci. 45, 2807-2812.

Osakada, F., Ikeda, H., Mandai, M., Wataya, T., Watanabe, K., Yoshimura, N., et al. (2008). Toward the generation of rod and cone photoreceptors from mouse, monkey and human embryonic stem cells. Nat. Biotechnol. 26, 215-224. doi: $10.1038 /$ nbt1384

Osakada, F., Jin, Z. B., Hirami, Y., Ikeda, H., Danjyo, T., Watanabe, K., et al. (2009). In vitro differentiation of retinal cells from human pluripotent stem cells by small-molecule induction. J. Cell Sci. 122, 3169-3179. doi: 10.1242/jcs.05 0393

Pacitti, D., Privolizzi, R., and Bax, B. E. (2019). Organs to cells and cells to organoids: the evolution of in vitro central nervous system modelling. Front. Cell. Neurosci. 13:129. doi: 10.3389/fncel.2019.00129

Palczewski, K. (2014). Chemistry and biology of the initial steps in vision: the Friedenwald lecture. Invest. Ophthalmol. Vis. Sci. 55, 6651-6672. 
Pandit, T., Jidigam, V. K., Patthey, C., and Gunhaga, L. (2015). Neural retina identity is specified by lens-derived BMP signals. Development 142, 1850-1859. doi: $10.1242 /$ dev. 123653

Pearring, J. N., Salinas, R. Y., Baker, S. A., and Arshavsky, V. Y. (2013). Protein sorting, targeting and trafficking in photoreceptor cells. Prog. Retin. Eye Res. 36, 24-51. doi: 10.1016/j.preteyeres.2013.03.002

Perrimon, N., Pitsouli, C., and Shilo, B. Z. (2012). Signaling mechanisms controlling cell fate and embryonic patterning. Cold Spring Harb. Perspect. Biol. 4:a005975. doi: 10.1101/cshperspect.a005975

Perron, M., Boy, S., Amato, M. A., Viczian, A., Koebernick, K., Pieler, T., et al. (2003). A novel function for Hedgehog signalling in retinal pigment epithelium differentiation. Development 130, 1565-1577. doi: 10.1242/dev. 00391

Petersen-Jones, S. M. (1998). Animal models of human retinal dystrophies. Eye (Lond) 12(Pt 3b), 566-570. doi: 10.1038/eye.1998.146

Petersen-Jones, S. M., Occelli, L. M., Winkler, P. A., Lee, W., Sparrow, J. R., Tsukikawa, M., et al. (2018). Patients and animal models of CNGbeta1-deficient retinitis pigmentosa support gene augmentation approach. J. Clin. Invest. 128, 190-206. doi: $10.1172 /$ jci95161

Pinzon-Guzman, C., Zhang, S. S., and Barnstable, C. J. (2011). Specific protein kinase $\mathrm{C}$ isoforms are required for rod photoreceptor differentiation. J. Neurosci. 31, 18606-18617. doi: 10.1523/jneurosci.2578-11.2011

Pittack, C., Grunwald, G. B., and Reh, T. A. (1997). Fibroblast growth factors are necessary for neural retina but not pigmented epithelium differentiation in chick embryos. Development 124, 805-816.

Prabhudesai, S. N., Cameron, D. A., and Stenkamp, D. L. (2005). Targeted effects of retinoic acid signaling upon photoreceptor development in zebrafish. Dev. Biol. 287, 157-167. doi: 10.1016/j.ydbio.2005.08.045

Pugh, E. N. Jr., and Lamb, T. D. (1993). Amplification and kinetics of the activation steps in phototransduction. Biochim. Biophys. Acta 1141, 111-149. doi: 10. 1016/0005-2728(93)90038-h

Qin, Z., Kidd, A. R. III, Thomas, J. L., Poss, K. D., Hyde, D. R., Raymond, P. A., et al. (2011). FGF signaling regulates rod photoreceptor cell maintenance and regeneration in zebrafish. Exp. Eye Res. 93, 726-734. doi: 10.1016/j.exer.2011. 09.003

Rachel, R. A., Li, T., and Swaroop, A. (2012a). Photoreceptor sensory cilia and ciliopathies: focus on CEP290, RPGR and their interacting proteins. Cilia 1:22. doi: 10.1186/2046-2530-1-22

Rachel, R. A., May-Simera, H. L., Veleri, S., Gotoh, N., Choi, B. Y., MurgaZamalloa, C., et al. (2012b). Combining Cep290 and Mkks ciliopathy alleles in mice rescues sensory defects and restores ciliogenesis. J. Clin. Invest. 122, 1233-1245. doi: 10.1172/jci60981

Radtke, N. D., Aramant, R. B., Petry, H. M., Green, P. T., Pidwell, D. J., and Seiler, M. J. (2008). Vision improvement in retinal degeneration patients by implantation of retina together with retinal pigment epithelium. Am. J. Ophthalmol. 146, 172-182.

Radtke, N. D., Aramant, R. B., Seiler, M. J., Petry, H. M., and Pidwell, D. (2004). Vision change after sheet transplant of fetal retina with retinal pigment epithelium to a patient with retinitis pigmentosa. Arch. Ophthalmol. 122, 1159-1165.

Radtke, N. D., Seiler, M. J., Aramant, R. B., Petry, H. M., and Pidwell, D. J. (2002). Transplantation of intact sheets of fetal neural retina with its retinal pigment epithelium in retinitis pigmentosa patients. Am. J. Ophthalmol. 133, 544-550. doi: 10.1016/s0002-9394(02)01322-3

Raftery, J., Clegg, A., Jones, J., Tan, S. C., and Lotery, A. (2007). Ranibizumab (Lucentis) versus bevacizumab (Avastin): modelling cost effectiveness. $\mathrm{Br}$. J. Ophthalmol. 91, 1244-1246. doi: 10.1136/bjo.2007.116616

Ramsden, C. M., Powner, M. B., Carr, A. J., Smart, M. J., da Cruz, L., and Coffey, P. J. (2013). Stem cells in retinal regeneration: past, present and future. Development $140,2576-2585$.

Ray, T. A., and Kay, J. N. (2015). Following directions from the retina to the brain. Neuron 86, 855-857. doi: 10.1016/j.neuron.2015.05.017

Raymond, S. M., and Jackson, I. J. (1995). The retinal pigmented epithelium is required for development and maintenance of the mouse neural retina. Curr. Biol. 5, 1286-1295. doi: 10.1016/s0960-9822(95)00255-7

Redmond, T. M., Yu, S., Lee, E., Bok, D., Hamasaki, D., Chen, N., et al. (1998). Rpe65 is necessary for production of 11-cis-vitamin A in the retinal visual cycle. Nat. Genet. 20, 344-351. doi: 10.1038/3813
Remington, L. A. (2012). "Chapter 7 - Ocular embryology," in Clinical Anatomy and Physiology of the Visual System, 3rd Edn, ed. L. A. Remington (Saint Louis, MO: Butterworth-Heinemann), 123-143. doi: 10.1016/b978-1-4377-1926-0. 10007-4

Rhinn, M., and Dolle, P. (2012). Retinoic acid signalling during development. Development 139, 843-858. doi: 10.1242/dev.065938

Riesenberg, A. N., Liu, Z., Kopan, R., and Brown, N. L. (2009). Rbpj cell autonomous regulation of retinal ganglion cell and cone photoreceptor fates in the mouse retina. J. Neurosci. 29, 12865-12877. doi: 10.1523/jneurosci.338209.2009

Rodriguez-de la Rosa, L., Fernandez-Sanchez, L., Germain, F., Murillo-Cuesta, S., Varela-Nieto, I., de la Villa, P., et al. (2012). Age-related functional and structural retinal modifications in the Igf1-/- null mouse. Neurobiol. Dis. 46, 476-485. doi: 10.1016/j.nbd.2012.02.013

Rosenfeld, P. J., Brown, D. M., Heier, J. S., Boyer, D. S., Kaiser, P. K., Chung, C. Y., et al. (2006). Ranibizumab for neovascular age-related macular degeneration. N. Engl. J. Med. 355, 1419-1431.

Rozet, J. M., Perrault, I., Gigarel, N., Souied, E., Ghazi, I., Gerber, S., et al. (2002). Dominant X linked retinitis pigmentosa is frequently accounted for by truncating mutations in exon ORF15 of the RPGR gene. J. Med. Genet. 39, 284-285. doi: 10.1136/jmg.39.4.284

Rudnicka, A. R., Kapetanakis, V. V., Jarrar, Z., Wathern, A. K., Wormald, R., Fletcher, A. E., et al. (2015). Incidence of late-stage age-related macular degeneration in American Whites: systematic review and meta-analysis. Am. J. Ophthalmol. 160, 85-93.e3. doi: 10.1016/j.ajo.2015.04.003

Saari, J. C. (2000). Biochemistry of visual pigment regeneration: the Friedenwald lecture. Invest. Ophthalmol. Vis. Sci. 41, 337-348.

Sakagami, K., Gan, L., and Yang, X. J. (2009). Distinct effects of Hedgehog signaling on neuronal fate specification and cell cycle progression in the embryonic mouse retina. J. Neurosci. 29, 6932-6944. doi: 10.1523/jneurosci.0289-09. 2009

Salido, E. M., and Ramamurthy, V. (2019). Proteoglycan IMPG2 shapes the interphotoreceptor matrix and modulates vision. bioRxiv [Preprint]. doi: 10. 1523/JNEUROSCI.2994-19.2020 bioRxiv: 859116,

Salinas, R. Y., Pearring, J. N., Ding, J. D., Spencer, W. J., Hao, Y., and Arshavsky, V. Y. (2017). Photoreceptor discs form through peripherindependent suppression of ciliary ectosome release. J. Cell Biol. 216, 1489-1499. doi: $10.1083 /$ jcb.201608081

Sarwar, S., Clearfield, E., Soliman, M. K., Sadiq, M. A., Baldwin, A. J., Hanout, M., et al. (2016). Aflibercept for neovascular age-related macular degeneration. Cochrane Database Syst. Rev. 2:CD011346.

Schlecht, A., Leimbeck, S. V., Jägle, H., Feuchtinger, A., Tamm, E. R., and Braunger, B. M. (2017). Deletion of endothelial transforming growth factor\&\#x2013;\&\#x3b2; signaling leads to choroidal neovascularization. Am. J. Pathol. 187, 2570-2589.

Schlueter, P. J., Peng, G., Westerfield, M., and Duan, C. (2007). Insulin-like growth factor signaling regulates zebrafish embryonic growth and development by promoting cell survival and cell cycle progression. Cell Death Differ. 14, 1095-1105. doi: 10.1038/sj.cdd.4402109

Schwartz, S. D., Hubschman, J. P., Heilwell, G., Franco-Cardenas, V., Pan, C. K., Ostrick, R. M., et al. (2012). Embryonic stem cell trials for macular degeneration: a preliminary report. Lancet $379,713-720$. doi: 10.1016/s01406736(12)60028-2

Schwartz, S. D., Regillo, C. D., Lam, B. L., Eliott, D., Rosenfeld, P. J., Gregori, N. Z., et al. (2015). Human embryonic stem cell-derived retinal pigment epithelium in patients with age-related macular degeneration and Stargardt's macular dystrophy: follow-up of two open-label phase 1/2 studies. Lancet 385, 509-516. doi: 10.1016/s0140-6736(14)61376-3

Schwartz, S. D., Tan, G., Hosseini, H., and Nagiel, A. (2016). Subretinal transplantation of embryonic stem cell-derived retinal pigment epithelium for the treatment of macular degeneration: an assessment at 4 years. Invest. Ophthalmol. Vis. Sci. 57, ORSFc1-ORSFc9.

Schwarz, N., Lane, A., Jovanovic, K., Parfitt, D. A., Aguila, M., Thompson, C. L., et al. (2017). Arl3 and RP2 regulate the trafficking of ciliary tip kinesins. Hum. Mol. Genet. 26, 2480-2492. doi: 10.1093/hmg/ddx143

Seiler, M. J., and Aramant, R. B. (2012). Cell replacement and visual restoration by retinal sheet transplants. Prog. Retin. Eye Res. 31, 661-687. doi: 10.1016/j. preteyeres.2012.06.003 
Seiler, M. J., Aramant, R. B., Thomas, B. B., Peng, Q., Sadda, S. R., and Keirstead, H. S. (2010). Visual restoration and transplant connectivity in degenerate rats implanted with retinal progenitor sheets. Eur J. Neurosci. 31, 508-520. doi: 10.1111/j.1460-9568.2010.07085.x

Seiler, M. J., Lin, R. E., McLelland, B. T., Mathur, A., Lin, B., Sigman, J., et al. (2017). Vision recovery and connectivity by fetal retinal sheet transplantation in an immunodeficient retinal degenerate rat model. Invest. Ophthalmol. Vis. Sci. 58, 614-630.

Sharon, D., Sandberg, M. A., Caruso, R. C., Berson, E. L., and Dryja, T. P. (2003). Shared mutations in NR2E3 in enhanced S-cone syndrome, goldmann-Favre syndrome, and many cases of clumped pigmentary retinal degeneration. Arch. Ophthalmol. 121, 1316-1323.

Shekhar, K., Lapan, S. W., Whitney, I. E., Tran, N. M., Macosko, E. Z., Kowalczyk, M., et al. (2016). Comprehensive classification of retinal bipolar neurons by single-cell transcriptomics. Cell 166, 1308-1323.e30. doi: 10.1016/j.cell.2016. 07.054

Shen, Q., Zhong, W., Jan, Y. N., and Temple, S. (2002). Asymmetric numb distribution is critical for asymmetric cell division of mouse cerebral cortical stem cells and neuroblasts. Development 129, 4843-4853.

Shirai, H., Mandai, M., Matsushita, K., Kuwahara, A., Yonemura, S., Nakano, T., et al. (2016). Transplantation of human embryonic stem cell-derived retinal tissue in two primate models of retinal degeneration. Proc. Natl. Acad. Sci. U.S.A. 113, E81-E90.

Siegert, S., Cabuy, E., Scherf, B. G., Kohler, H., Panda, S., Le, Y. Z., et al. (2012). Transcriptional code and disease map for adult retinal cell types. Nat. Neurosci. 15, 487-495. doi: 10.1038/nn.3032

Singh, B., and Armstrong, D. T. (1997). Insulin-like growth factor-1, a component of serum that enables porcine cumulus cells to expand in response to folliclestimulating hormone in vitro. Biol. Reprod. 56, 1370-1375. doi: 10.1095/ biolreprod56.6.1370

Singh, M. S., Charbel Issa, P., Butler, R., Martin, C., Lipinski, D. M., Sekaran, S., et al. (2013). Reversal of end-stage retinal degeneration and restoration of visual function by photoreceptor transplantation. Proc. Natl. Acad. Sci. U.S.A. 110, 1101-1106. doi: 10.1073/pnas.1119416110

Singh, R. K., Kolandaivelu, S., and Ramamurthy, V. (2014). Early alteration of retinal neurons in Aipl1-/- animals. Invest. Ophthalmol. Vis. Sci. 55, 3081-3092.

Singh, R. K., Mallela, R. K., Cornuet, P. K., Reifler, A. N., Chervenak, A. P., West, M. D., et al. (2015). Characterization of three-dimensional retinal tissue derived from human embryonic stem cells in adherent monolayer cultures. Stem Cells Dev. 24, 2778-2795. doi: 10.1089/scd.2015.0144

Singh, R. K., Mallela, R. K., Hayes, A., Dunham, N. R., Hedden, M. E., Enke, R. A., et al. (2017). Dnmt1, Dnmt3a and Dnmt3b cooperate in photoreceptor and outer plexiform layer development in the mammalian retina. Exp. Eye Res. 159, 132-146. doi: 10.1016/j.exer.2016.11.014

Singh, R. K., Occelli, L. M., Binette, F., Petersen-Jones, S. M., and Nasonkin, I. O. (2019). Transplantation of human embryonic stem cell-derived retinal tissue in the subretinal space of the cat eye. Stem Cells Dev. 28, 1151-1166. doi: 10.1089/scd.2019.0090

Slijkerman, R. W., Song, F., Astuti, G. D., Huynen, M. A., van Wijk, E., Stieger, K., et al. (2015). The pros and cons of vertebrate animal models for functional and therapeutic research on inherited retinal dystrophies. Prog. Retin. Eye Res. 48, 137-159. doi: 10.1016/j.preteyeres.2015.04.004

Smith, J. N., Walker, H. M., Thompson, H., Collinson, J. M., Vargesson, N., and Erskine, L. (2018). Lens-regulated retinoic acid signalling controls expansion of the developing eye. Development 145:dev167171. doi: 10.1242/dev.167171

Song, M. J., and Bharti, K. (2016). Looking into the future: using induced pluripotent stem cells to build two and three dimensional ocular tissue for cell therapy and disease modeling. Brain Res. 1638, 2-14. doi: 10.1016/j.brainres. 2015.12.011

Sparrow, J. R., Hicks, D., and Hamel, C. P. (2010). The retinal pigment epithelium in health and disease. Curr. Mol. Med. 10, 802-823.

Spence, J. R., Madhavan, M., Ewing, J. D., Jones, D. K., Lehman, B. M., and Del RioTsonis, K. (2004). The hedgehog pathway is a modulator of retina regeneration. Development 131, 4607-4621. doi: 10.1242/dev.01298

Strauss, O. (2005). The retinal pigment epithelium in visual function. Physiol. Rev. 85, 845-881. doi: 10.1152/physrev.00021.2004

Stronks, H. C., and Dagnelie, G. (2014). The functional performance of the Argus II retinal prosthesis. Expert Rev. Med. Devices 11, 23-30. doi: 10.1586/17434440. 2014.862494
Strunnikova, N. V., Maminishkis, A., Barb, J. J., Wang, F., Zhi, C., Sergeev, Y., et al. (2010). Transcriptome analysis and molecular signature of human retinal pigment epithelium. Hum. Mol. Genet. 19, 2468-2486. doi: 10.1093/hmg/ ddq129

Sun, Y., and Smith, L. E. H. (2018). Retinal vasculature in development and diseases. Annu. Rev. Vis. Sci. 4, 101-122. doi: 10.1146/annurev-vision-091517034018

Sunness, J. S., Gonzalez-Baron, J., Applegate, C. A., Bressler, N. M., Tian, Y., Hawkins, B., et al. (1999). Enlargement of atrophy and visual acuity loss in the geographic atrophy form of age-related macular degeneration. Ophthalmology 106, 1768-1779. doi: 10.1016/s0161-6420(99)90340-8

Swaroop, A., Kim, D., and Forrest, D. (2010). Transcriptional regulation of photoreceptor development and homeostasis in the mammalian retina. Nat. Rev. Neurosci. 11, 563-576. doi: 10.1038/nrn2880

Swaroop, A., Xu, J. Z., Pawar, H., Jackson, A., Skolnick, C., and Agarwal, N. (1992). A conserved retina-specific gene encodes a basic motif/leucine zipper domain. Proc. Natl. Acad. Sci. U.S.A. 89, 266-270. doi: 10.1073/pnas.89.1.266

Takata, N., Abbey, D., Fiore, L., Acosta, S., Feng, R., Gil, H. J., et al. (2017). An eye organoid approach identifies Six 3 suppression of R-spondin 2 as a critical step in mouse neuroretina differentiation. Cell Rep. 21, 1534-1549. doi: 10.1016/j. celrep.2017.10.041

Tombran-Tink, J., and Barnstable, C. J. (2003). Therapeutic prospects for PEDF: more than a promising angiogenesis inhibitor. Trends Mol. Med. 9, 244-250. doi: 10.1016/s1471-4914(03)00074-1

Tombran-Tink, J., Chader, G. G., and Johnson, L. V. (1991). PEDF: a pigment epithelium-derived factor with potent neuronal differentiative activity. Exp. Eye Res. 53, 411-414. doi: 10.1016/0014-4835(91)90248-d

Tomita, K., Ishibashi, M., Nakahara, K., Ang, S. L., Nakanishi, S., Guillemot, F., et al. (1996). Mammalian hairy and enhancer of split homolog 1 regulates differentiation of retinal neurons and is essential for eye morphogenesis. Neuron 16, 723-734. doi: 10.1016/s0896-6273(00)80093-8

Tu, H. Y., Watanabe, T., Shirai, H., Yamasaki, S., Kinoshita, M., Matsushita, K., et al. (2018). Medium- to long-term survival and functional examination of human iPSC-derived retinas in rat and primate models of retinal degeneration. EBioMedicine 39, 562-574. doi: 10.1016/j.ebiom.2018.11.028

Vajaranant, T. S., Wu, S., Torres, M., and Varma, R. (2012). The changing face of primary open-angle glaucoma in the United States: demographic and geographic changes from 2011 to 2050. Am. J. Ophthalmol. 154, 303-314.e3. doi: 10.1016/j.ajo.2012.02.024

van Adel, B. A., Arnold, J. M., Phipps, J., Doering, L. C., and Ball, A. K. (2005). Ciliary neurotrophic factor protects retinal ganglion cells from axotomyinduced apoptosis via modulation of retinal glia in vivo. J. Neurobiol. 63, 215-234. doi: 10.1002/neu.20117

Vander Heiden, M. G., Cantley, L. C., and Thompson, C. B. (2009). Understanding the Warburg effect: the metabolic requirements of cell proliferation. Science 324, 1029-1033. doi: 10.1126/science.1160809

Varma, R., Vajaranant, T. S., Burkemper, B., Wu, S., Torres, M., Hsu, C., et al. (2016). Visual impairment and blindness in adults in the United States: demographic and geographic variations from 2015 to 2050. JAMA Ophthalmol. 134, 802-809.

Veltel, S., Gasper, R., Eisenacher, E., and Wittinghofer, A. (2008). The retinitis pigmentosa 2 gene product is a GTPase-activating protein for Arf-like 3. Nat. Struct. Mol. Biol. 15, 373-380. doi: 10.1038/nsmb.1396

Vingerling, J. R., Dielemans, I., Hofman, A., Grobbee, D. E., Hijmering, M., Kramer, C. F., et al. (1995). The prevalence of age-related maculopathy in the Rotterdam Study. Ophthalmology 102, 205-210. doi: 10.1016/s0161-6420(95) 31034-2

Vogel-Hopker, A., Momose, T., Rohrer, H., Yasuda, K., Ishihara, L., and Rapaport, D. H. (2000). Multiple functions of fibroblast growth factor-8 (FGF-8) in chick eye development. Mech. Dev. 94, 25-36. doi: 10.1016/s0925-4773(00)00 320-8

Volkner, M., Zschatzsch, M., Rostovskaya, M., Overall, R. W., Busskamp, V., Anastassiadis, K., et al. (2016). Retinal organoids from pluripotent stem cells efficiently recapitulate retinogenesis. Stem Cell Rep. 6, 525-538. doi: 10.1016/j. stemcr.2016.03.001

Volland, S., Esteve-Rudd, J., Hoo, J., Yee, C., and Williams, D. S. (2015a). A comparison of some organizational characteristics of the mouse central retina and the human macula. PLoS One 10:e0125631. doi: 10.1371/journal.pone. 0125631 
Volland, S., Hughes, L. C., Kong, C., Burgess, B. L., Linberg, K. A., Luna, G., et al. (2015b). Three-dimensional organization of nascent rod outer segment disk membranes. Proc. Natl. Acad. Sci. U.S.A. 112, 14870-14875. doi: 10.1073/pnas. 1516309112

Volpert, K. N., Tombran-Tink, J., Barnstable, C., and Layer, P. G. (2009). PEDF and GDNF are key regulators of photoreceptor development and retinal neurogenesis in reaggregates from chick embryonic retina. J. Ocul. Biol. Dis. Infor. 2, 1-11. doi: 10.1007/s12177-009-9014-x

Wadman, M. (2015). The truth about fetal tissue research. Nature 528, 179-181.

Wahlin, K. J., Maruotti, J. A., Sripathi, S. R., Ball, J., Angueyra, J. M., Kim, C., et al. (2017). Photoreceptor outer segment-like structures in long-term 3D retinas from human pluripotent stem cells. Sci. Rep. 7:766.

Wallace, V. A. (2011). Concise review: making a retina-from the building blocks to clinical applications. Stem Cells 29, 412-417. doi: 10.1002/stem.602

Wang, J. S., Estevez, M. E., Cornwall, M. C., and Kefalov, V. J. (2009). Intraretinal visual cycle required for rapid and complete cone dark adaptation. Nat. Neurosci. 12, 295-302. doi: 10.1038/nn.2258

Wang, J. S., and Kefalov, V. J. (2011). The cone-specific visual cycle. Prog. Retin. Eye Res. 30, 115-128. doi: 10.1016/j.preteyeres.2010.11.001

Wang, Y., Zhang, D., Zhang, Y., Ni, N., Tang, Z., Bai, Z., et al. (2018). Insulinlike growth factor-1 regulation of retinal progenitor cell proliferation and differentiation. Cell Cycle 17, 515-526. doi: 10.1080/15384101.2018.1431594

Wang, Y. P., Dakubo, G., Howley, P., Campsall, K. D., Mazarolle, C. J., Shiga, S. A., et al. (2002). Development of normal retinal organization depends on Sonic hedgehog signaling from ganglion cells. Nat. Neurosci. 5, 831-832. doi: $10.1038 /$ nn911

Warburg, O. (1928). "Über die klassifizierung tierischer gewebe nach ihrem stoffwechsel," in Über die Katalytischen Wirkungen der Lebendigen Substanz: Arbeiten aus dem Kaiser Wilhelm-Institut für Biologie · Berlin-Dahlem, ed. O. Warburg (Berlin: Springer), 510-514. doi: 10.1007/978-3-642-47774-4_35

Warburg, O., Wind, F., and Negelein, E. (1927). The metabolism of tumors in the body. J. Gen. Physiol. 8, 519-530. doi: 10.1085/jgp.8.6.519

Weinreb, R. N., Aung, T., and Medeiros, F. A. (2014). The pathophysiology and treatment of glaucoma: a review. JAMA 311, 1901-1911.

Wheway, G., Parry, D. A., and Johnson, C. A. (2014). The role of primary cilia in the development and disease of the retina. Organogenesis 10, 69-85. doi: 10.4161/org.26710

Wickham, L., Lewis, G. P., Charteris, D. G., and Fisher, S. K. (2013). “Chapter 29 Cellular effects of detachment and reattachment on the neural retina and the retinal pigment epithelium," in Retina, 5th Edn, eds S. J. Ryan, S. R. Sadda, D. R. Hinton, A. P. Schachat, S. R. Sadda, C. P. Wilkinson, et al. (London: W.B. Saunders), 605-617. doi: 10.1016/b978-1-4557-0737-9.00029-1

Wong, W. L., Su, X., Li, X., Cheung, C. M., Klein, R., Cheng, C. Y., et al. (2014). Global prevalence of age-related macular degeneration and disease burden projection for 2020 and 2040: a systematic review and meta-analysis. Lancet Glob. Health 2, e106-e116. doi: 10.1016/s2214-109x(13)70145-1

Wong-Riley, M. T. (2010). Energy metabolism of the visual system. Eye Brain 2, 99-116.

Wu, J., Mak, H. K., Chan, Y. K., Lin, C., Kong, C., Leung, C. K. S., et al. (2019). An in vitro pressure model towards studying the response of primary retinal ganglion cells to elevated hydrostatic pressures. Sci. Rep. 9:9057.

Xing, T., Hass, D. T., Zhang, S. S., and Barnstable, C. J. (2018). The 3phosphoinositide-dependent protein kinase 1 inhibits rod photoreceptor development. Front. Cell Dev. Biol. 6:134. doi: 10.3389/fcell.2018.00134

Yang, N., Caratti, G., Ince, L. M., Poolman, T. M., Trebble, P. J., Holt, C. M., et al. (2014). Serum cholesterol selectively regulates glucocorticoid sensitivity through activation of JNK. J. Endocrinol. 223, 155-166. doi: 10.1530/joe-140456

Yao, K., Qiu, S., Tian, L., Snider, W. D., Flannery, J. G., Schaffer, D. V., et al. (2016). Wnt regulates proliferation and neurogenic potential of muller glial cells via a Lin28/let-7 miRNA-dependent pathway in adult mammalian retinas. Cell Rep. 17, 165-178. doi: 10.1016/j.celrep.2016.08.078

Yaron, O., Farhy, C., Marquardt, T., Applebury, M., and Ashery-Padan, R. (2006). Notchl functions to suppress cone-photoreceptor fate specification in the developing mouse retina. Development 133, 1367-1378. doi: 10.1242/dev.02311
Ye, X., Wang, Y., and Nathans, J. (2010). The Norrin/Frizzled4 signaling pathway in retinal vascular development and disease. Trends Mol. Med. 16, 417-425. doi: 10.1016/j.molmed.2010.07.003

Yeo, N. J. Y., Chan, E. J. J., and Cheung, C. (2019). Choroidal neovascularization: mechanisms of endothelial dysfunction. Front. Pharmacol. 10:1363. doi: 10. 3389/fphar.2019.01363

Yi, X., Schubert, M., Peachey, N. S., Suzuma, K., Burks, D. J., Kushner, J. A., et al. (2005). Insulin receptor substrate 2 is essential for maturation and survival of photoreceptor cells. J. Neurosci. 25, 1240-1248. doi: 10.1523/jneurosci.366404.2005

Yildiz, O., and Khanna, H. (2012). Ciliary signaling cascades in photoreceptors. Vis. Res 75, 112-116. doi: 10.1016/j.visres.2012.08.007

Young, R. W. (1967). The renewal of photoreceptor cell outer segments. J. Cell Biol. 33, 61-72. doi: 10.1083/jcb.33.1.61

Yu, C., Mazerolle, C. J., Thurig, S., Wang, Y., Pacal, M., Bremner, R., et al. (2006). Direct and indirect effects of hedgehog pathway activation in the mammalian retina. Mol. Cell. Neurosci. 32, 274-282. doi: 10.1016/j.mcn.2006.05.002

Zeiss, C. J. (2010). Animals as models of age-related macular degeneration: an imperfect measure of the truth. Vet. Pathol. 47, 396-413. doi: 10.1177/ 0300985809359598

Zhang, X. M., and Yang, X. J. (2001a). Regulation of retinal ganglion cell production by Sonic hedgehog. Development 128, 943-957.

Zhang, X. M., and Yang, X. J. (2001b). Temporal and spatial effects of Sonic hedgehog signaling in chick eye morphogenesis. Dev. Biol. 233, 271-290. doi: 10.1006/dbio.2000.0195

Zhang, Y., Strehin, I., Bedelbaeva, K., Gourevitch, D., Clark, L., Leferovich, J., et al. (2015). Drug-induced regeneration in adult mice. Sci. Transl. Med. 7:290ra92. doi: $10.1126 /$ scitranslmed.3010228

Zhao, C., Wang, Q., and Temple, S. (2017). Stem cell therapies for retinal diseases: recapitulating development to replace degenerated cells. Development 144, 1368-1381. doi: 10.1242/dev.133108

Zhao, S., Hung, F. C., Colvin, J. S., White, A., Dai, W., Lovicu, F. J., et al. (2001). Patterning the optic neuroepithelium by FGF signaling and Ras activation. Development 128, 5051-5060.

Zheng, M., Zhang, Z., Zhao, X., Ding, Y., and Han, H. (2010). The Notch signaling pathway in retinal dysplasia and retina vascular homeostasis. J. Genet. Genomics 37, 573-582. doi: 10.1016/s1673-8527(09)60077-1

Zheng, M. H., Shi, M., Pei, Z., Gao, F., Han, H., and Ding, Y. Q. (2009). The transcription factor RBP-J is essential for retinal cell differentiation and lamination. Mol. Brain 2:38. doi: 10.1186/1756-6606-2-38

Zheng, W., Meng, Q., Wang, H., Yan, F., Little, P. J., Deng, X., et al. (2018). IGF1 -mediated survival from induced death of human primary cultured retinal pigment epithelial cells is mediated by an akt-dependent signaling pathway. Mol. Neurobiol. 55, 1915-1927. doi: 10.1007/s12035-017-0447-0

Zhong, X., Gutierrez, C., Xue, T., Hampton, C., Vergara, M. N., Cao, L. H., et al. (2014). Generation of three-dimensional retinal tissue with functional photoreceptors from human iPSCs. Nat. Commun. 5:4047.

Zhou, S., Flamier, A., Abdouh, M., Tetreault, N., Barabino, A., Wadhwa, S., et al. (2015). Differentiation of human embryonic stem cells into cone photoreceptors through simultaneous inhibition of BMP, TGFbeta and Wnt signaling. Development 142, 3294-3306. doi: 10.1242/dev.125385

Conflict of Interest: Both authors were employed by the company Lineage Cell Therapeutics.

The authors declare that the research was conducted in the absence of any commercial or financial relationships that could be construed as a potential conflict of interest.

Copyright (c) 2020 Singh and Nasonkin. This is an open-access article distributed under the terms of the Creative Commons Attribution License (CC BY). The use, distribution or reproduction in other forums is permitted, provided the original author(s) and the copyright owner(s) are credited and that the original publication in this journal is cited, in accordance with accepted academic practice. No use, distribution or reproduction is permitted which does not comply with these terms. 